\title{
Therapeutic Vaccines for Cancer Immunotherapy
}

Jie Wang ${ }^{1,2}$, Muhetaerjiang Mamuti ${ }^{1,2}$, Hao Wang $^{*, 1,2}$

${ }^{1}$ CAS Center for Excellence in Nanoscience, CAS Key Laboratory for Biological

Effects of Nanomaterials and Nanosafety, National Center for Nanoscience and

Technology (NCNST), No. 11 Beiyitiao, Zhongguancun, Beijing, China;

${ }^{2}$ Center of Materials Science and Optoelectronics Engineering, University of Chinese Academy of Sciences, Beijing 100049, P.R. China;

KEYWORDS: vaccine, immunotherapy, tumour antigen, adjuvant, combinational delivery

ABSTRACT: The rapid development of nanobiotechnology have enabled the progress of therapeutic cancer vaccines. It stimulates host innate immune response by tumour antigens followed with cascade adaptive response against cancer. However, improved anti-tumour immune response is still highly demanded since the unsatisfied clinic performance of vaccine in tumour inhibition and regression. To date, complicated tumour immunosuppressive environment and suboptimal design are main obstacles for therapeutic cancer vaccines. The optimization for tumour antigens, vaccine delivery pathways, proper adjuvants for innate immune response initiation, along with the reprogramming of tumour immunosuppressive environment are essential for 
therapeutic cancer vaccines in triggering adequate anti-tumour immune response. In this review, we aim to overview challenges and strategies for enhancing efficacy of therapeutic vaccines. We will start with the summary of the available tumour antigens and their properties, then the optimal strategies for vaccine delivery. Subsequently the vaccines adjuvants focused on the intrinsic adjuvant properties of nanostructures are further discussed. Finally, we tend to summarize the combinational strategies with therapeutic cancer vaccines and discuss their positive impact in cancer immunity.

\section{INTRODUCTION}

The importance of therapeutic vaccines in cancer immunotherapies presents a step rise increase over the past few decades. By harnessing the patients' own immune systems, it activates the cascade antigen-specific response of immune system and ultimately achieve the killing effects of tumour cells ${ }^{1-2}$. Different from traditional vaccines, the therapeutic cancer vaccines reconstruct the body' immune system that tolerate tumour antigens before and also function as modulator to turn the "cold" tumours into "hot" tumours. In addition, it also plays a decisive role in preventing tumour metastasis and recurrence ${ }^{3-4}$. As early as the 1890 s, it was discovered that patients with advanced cancer had spontaneous tumour regression after intervened with streptococcus infection and was found that the Coley's toxin was the major factor contributing to the enhancement of immune response ${ }^{5}$. Later the mechanism was concluded that the Coley's toxin could regulate innate immunity non-specifically and break peripheral tolerance ${ }^{6}$. Subsequently, the researchers tried to make use of tumour 
antigens to activate the host immune system and achieved tumours ablation effect ${ }^{7}$. In 2010, the first commercialized therapeutic cancer vaccine, named as Provenge, was approved by FDA for advanced prostate cancer, marked as a milestone in cancer vaccines. Up to now, numerous encouraging results were achieved in patients with various cancers ${ }^{8}$.

However, whether the therapeutic cancer vaccine will produce desired results was influenced by many factors and faced multiple challanges ${ }^{9-10}$. The first is the immunogenicity of tumour antigens. The immunogenicity of tumour antigens determines the effectiveness of anti-tumour immune response. It is necessary to discover and identify tumour specific antigen (TSA) that are specifically expressed in tumour cells, named neoantigens, which have high immunogenicity and can trigger immune responses more effectively without damage normal tissues compared with tumour associated antigens (TAA) ${ }^{11-13}$. In addition, the delivery of vaccines is also critical. Targeting lymph node has been proved to be favorable for therapeutic cancer vaccines compared with traditional peripheral method, the extensive attention was focused on strategies for enhancing lymph node delivery and further improve cross presentation and minimize side effects of vaccine components ${ }^{14-15}$. The limited adjuvants were approved by FDA and fewer is available for therapeutic cancer vaccines because most approved adjuvants tend to induce humoral immunity ${ }^{16}$, the unclear mechanism of some adjuvant further impede vaccine development ${ }^{16}$. Moreover, the efficacy of antitumour immune response is mostly impacted by tumour immunosuppressive environment ${ }^{17-18}$. The intricate tumour microenvironment 
attenuates immunosurveillance to support tumour growth and metastasis ${ }^{19}$. Overcoming the immunosuppressive microenvironment and improving effector T cells function are of benefit for cancer therapeutic vaccine design ${ }^{20}$.

The therapeutic cancer vaccines act on the innate immune system and produced pools of cytotoxic T cells that directly kill the tumour cells (Figure 1). Complicated tumour immunosuppressive network and suboptimal designs of current therapeutic cancer vaccines reminds us that deeper understanding on influential factors and how to achieve a successful tumour regression should be emphasized. In this review, we will summarize the key steps that affect the effectiveness of vaccines from the selection of tumour antigens, vaccine delivery, innate immune response initiation, and the combination therapies that potentially enhance the efficacy of cancer therapeutic vaccines, further propose rational strategies to the challenges of each step.

(1)

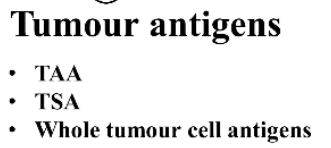

(2)

Adjuvants

- Immune stimulation

- enhance antigen availability

- regulate immune phenotype

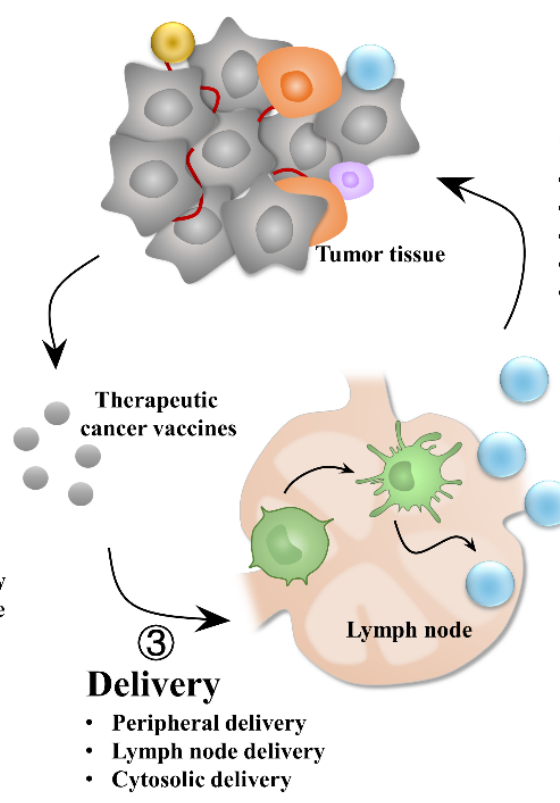

(4)

\section{Combinational therapy}

- Immune checkpoint block combination

Chemotherapy combination

Radiation combination

Antiangiogenic Combinations

- Inhibit immune evasion

Figure 1. Schematic illustration of immunity cycle for therapeutic cancer vaccines. 


\section{TUMOUR ANTIGENS}

Tumour antigens as the most important part in therapeutic cancer vaccines have made great progress in recent years. It can be brief divided into following categories: i) The TAAs with limited immunogenicity. ii) TSAs with higher immunogenicity. iii) Whole tumour cell antigens that without further identification and overcome heterogeneity of tumour antigens $^{7,21}$ (Figure 2). The representative tumour antigens in clinical trials are summarized in Table 1. Above all, whether the antigens could exhibit well immunogenicity to induce adequate antigen-specific immune response is an overarching priority.

2.1. Tumour Associated Antigens. Tumour associated antigens (TAAs) are defined as antigens that overexpressed on certain tumour cells but still existed on normal cells. There are many types of tumour antigens to choose from and each has its own unique advantages ${ }^{22-23}$. Tumour associated peptide antigens are one of the most widely studied antigens due to its easy synthesizability and strong biocompatibility ${ }^{24-25}$. The antigen epitope such as gp10025-33 from human melanoma antigen ${ }^{26}$, OVA257-264 and OVA $323-$ 339 from ovalbumin ${ }^{27}$, MUC1 glycosylated peptide expressed on epithelial tumour cells ${ }^{28}$ regarded as tumour associated antigen (TAA) have widely researched. Due to the diversity of antigen epitopes on a certain cancer, the immunogenicity of single peptide epitope in cancer vaccine seems too weak to elicit an adequate anti-cancer immune response. Moreover, it has proposed that the helper T-cell epitope is also important for cancer vaccines as it could improve the function of cytotoxic $\mathrm{T}$ cells. 
Therefore, the mixed multi-peptides and synthetic long peptide (SLP) vaccines that contained multi-epitopes seems more promising ${ }^{29-31}$. Another type is the nucleic acids that encoding to TAAs, including DNA and RNA vaccines, also appealing and rapidly developed $^{32-33}$. It is designed to translate into tumour antigen in cytoplasm and presented with MHC complex to the surface of antigen presenting cells (APCs). These vaccines usually simultaneously encode multiple antigen epitopes to induce both humoral and cellular immune response. Different from RNA vaccines, DNA vaccines need to deliver into nucleus in APCs, which seems less efficient and unsafe than RNA vaccines that are only delivered into cytoplasm ${ }^{32,34-35}$.

The weak immunogenicity of tumour associated antigen is one of the major challenges for cancer vaccines. One method to enhance immunogenicity is through remodel peptide antigen epitope by enhancing or extending affinity between epitopeMHC complex with $\mathrm{T}$ or $\mathrm{B}$ cell receptor, such as substitution of amino acids from peptide flanking residues or phosphorylation of amino acids that was not epitopebinding site ${ }^{36-37}$. Beside this, identify the antigens that specific expressed on tumour cells also highly enhance antigen immunogenicity. 


\section{A. Tumour associated antigen (TAA) and tumour specific antigen (TSA)}

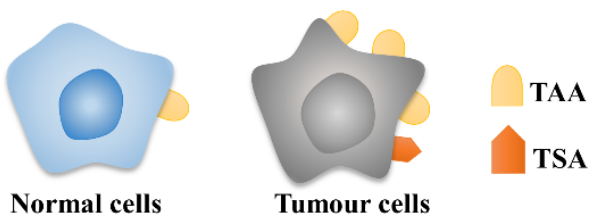

\section{B. Whole tumour cell antigen}

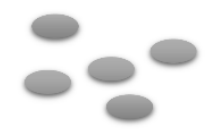

Tumour cell lysates

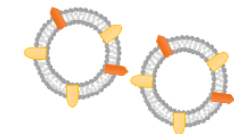

Tumour cell membrane
Tumour derived extracellular vesicles

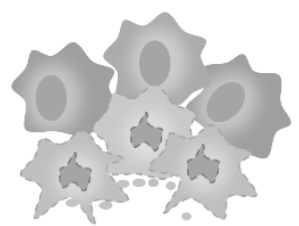

Autologous antigens generated by immunogenic cell death

Figure 2. The classification of tumour antigens. (A) different expression between TAA and TSA. (B) Strategies for producing whole tumour cell antigens.

2.2. Tumour Specific Antigens. Unlike TAAs, the tumour specific antigens (TSAs) characterized with strong tumour specificity and serve as an ideal target for cancer vaccines comparing with TAAs ${ }^{38}$. TSAs, also named as neoantigens, are abnormal proteins encoded by mutations in cancer cell genes, which are not subject to central tolerance and could produce a strong immune respons $\mathrm{e}^{39}$. However, the gene mutations presented individual differences. Therefore, the discovery and identification of neoantigens for personalized cancer vaccines is essential ${ }^{40-41}$. The construction of neoantigen-based cancer vaccine is achieved through multiple cascade steps including the identification of tumour mutation, the selection and optimization of epitopes with good immunogenicity to induce desired anti-tumour immune response. For example, the tumour cells were subjected to whole exosome-sequencing (WES) and RNA 
sequencing to identify nonsynonymous mutations, then the selection of long candidate peptides with 8 to 11 amino acids are needed to predicted H2-Kb binding or H2-Db binding with an affinity lower than $1000 \mathrm{nM}$. Subsequently, synthesize the twelve 20mer synthetic long peptide with mutated residues were synthesized to induce both CD4+ and CD8+ $\mathrm{T}$ cell responses ${ }^{42}$. However, the complex procedures, technical limitations, long production period, along with the high costs hinder its wider applications.

2.3. Whole Tumour Cell Antigens. Whole tumour cell antigen is composed of variety of tumour antigens that able to induce both $\mathrm{CD} 4^{+} \mathrm{T}$ helper and $\mathrm{CD} 8^{+}$cytotoxic lymphocytes immune response simultaneously. This strategy had drawn wide attention, such as tumour cell lysates ${ }^{43}$, tumour cell membranes ${ }^{44-45}$ and tumour-derived extracellular vesicles ${ }^{46-47}$, which contained multi-neoantigens without further prediction and indentation. The whole-tumour cell vaccine allows dendritic cells to process and present numerous tumour antigens, and is suitable for all patients regardless of their human leukocyte antigen (HLA) type. Research showed that using tumour cell lysates to pulse autologous DCs displayed encouraging results with longer disease-free interval (DFI) on vaccine maintenance in advanced ovarian cancer patients ${ }^{48}$. Moreover, the cancer cell membrane-derived antigens also be interested to develop as cancer vaccines. The tumour membrane also could load nanoparticles or adjuvants to further optimize vaccine behavior, such as enhance dendritic cells uptake. It effectively combated melanoma progression when combined with anti-PD-1 checkpoint blockade therapy ${ }^{45}$. However, the whole tumour cell produced vaccine also composed normal 
proteins or other cell components. The complicated composition may influence antitumour specific immune response. Another promising strategy that has been used in studies is the immunogenic cell death (ICD), which often induced by chemotherapy ${ }^{49}$, radiation $^{50}$ or other strategies ${ }^{51-54}$ to cause partial apoptosis of tumour cells and antigen release. The ICD-induced tumour death also could release immune stimulants and dander signals, such as adenosine triphosphate (ATP), calreticulin (CRT), high mobility group box 1 (HMGB1), Annexin A1 (ANXA1) and heat-shock proteins (HSPs), which could lead to immune cells recruitment and activation after recognize with their receptors. The activated immune cells could further kill the remained or metastatic tumour cells ${ }^{55}$. Further through with other cancer immunotherapies, this strategy is more convenient and feasible, effectively eliminating the individual differences. However, there are lots of issues should be considered that may impact the dead cells handled by immune system, such as the type of cell death, cell death pathway and other influences, and detailed mechanisms of ICD occurrence still need attention. Moreover, the ICD-inducing anticancer agents may loss efficacy when ICD related signals are suppressed or the immune effectors are damaged ${ }^{56-57}$.

In any case, tumour antigens as an important part of therapeutic cancer vaccines need to find and optimize techniques that can stimulate powerful tumour-specific immune responses, which is one of the great challenges in cancer vaccine development.

Table 1. Representative clinical trials of therapeutic cancer vaccines in phase 3. 


\begin{tabular}{|c|c|c|c|c|c|}
\hline Vaccine & $\begin{array}{l}\text { Targeted } \\
\text { antigen }\end{array}$ & Adjuvant & Combination & $\begin{array}{c}\text { Study } \\
\text { population }\end{array}$ & Identifier \\
\hline $\begin{array}{l}\text { Dendritic cell } \\
\text { vaccine }\end{array}$ & $\begin{array}{l}\text { Autologous } \\
\text { tumour cells }\end{array}$ & - & Bevacizumab & Glioblastoma & NCT04277221 \\
\hline $\begin{array}{l}\text { Dendritic cell } \\
\text { vaccine }\end{array}$ & $\begin{array}{l}\text { Autologous } \\
\text { tumour } \\
\text { mRNA }\end{array}$ & - & Temozolomide & Glioblastoma & NCT03548571 \\
\hline $\begin{array}{c}\text { Antigen } \\
\text { Pulsed } \\
\text { Dendritic Cells }\end{array}$ & $\begin{array}{l}\text { Autologous } \\
\text { tumour lysates }\end{array}$ & - & $\begin{array}{l}\text { FOLFOX6- } \\
\text { chemotherapy }\end{array}$ & $\begin{array}{c}\text { Metastatic } \\
\text { Colorectal } \\
\text { Cancer }\end{array}$ & NCT02503150 \\
\hline DCVAC/OvCa & $\begin{array}{l}\text { Autologous } \\
\text { tumour lysis }\end{array}$ & - & $\begin{array}{l}\text { Platinum and/or } \\
\text { bevacizumab }\end{array}$ & $\begin{array}{l}\text { Relapsed } \\
\text { Ovarian }\end{array}$ & NCT03905902 \\
\hline ProstAtak & $\begin{array}{c}\text { Autogolous } \\
\text { tumour } \\
\text { antigens }\end{array}$ & - & $\begin{array}{l}\text { Valacyclovir and } \\
\text { Radiation }\end{array}$ & $\begin{array}{l}\text { Localized } \\
\text { Prostate } \\
\text { Cancer }\end{array}$ & NCT01436968 \\
\hline NeuVax & $\begin{array}{l}\text { E75 peptide } \\
\text { acetate }\end{array}$ & GM-CSF & - & $\begin{array}{l}\text { Breast } \\
\text { Cancer }\end{array}$ & NCT01479244 \\
\hline EGF Vaccine & $\begin{array}{l}\text { Recombinant } \\
\text { human rEGF- } \\
\text { P64K }\end{array}$ & $\begin{array}{l}\text { Montanide } \\
\text { ISA } 51\end{array}$ & $\begin{array}{c}\text { Low dose of } \\
\text { cyclophosphamide }\end{array}$ & $\begin{array}{l}\text { Stage IV } \\
\text { Biomarker } \\
\text { Positive, } \\
\text { Wild Type } \\
\text { EGF-R } \\
\text { NSCLC }\end{array}$ & NCT02187367 \\
\hline CMB305 & NY-ESO-1 & $\begin{array}{l}\text { TLR-4 } \\
\text { agonist }\end{array}$ & Surgery & $\begin{array}{l}\text { Synovial } \\
\text { Sarcoma }\end{array}$ & NCT03520959 \\
\hline Rindopepimut & $\begin{array}{l}\text { EGFRvIII } \\
\text { protein }\end{array}$ & GM-CSF & Temozolomide & $\begin{array}{c}\text { EGFRvIII- } \\
\text { positive } \\
\text { Glioblastoma }\end{array}$ & NCT01480479 \\
\hline $\begin{array}{c}\text { Adagloxad } \\
\text { Simolenin/ } \\
\text { OBI-821 }\end{array}$ & Globo H & - & $\begin{array}{l}\text { Capecitabine or } \\
\text { platinum }\end{array}$ & $\begin{array}{c}\text { Triple } \\
\text { Negative } \\
\text { Breast } \\
\text { Cancer }\end{array}$ & NCT03562637 \\
\hline IMA901 & $\begin{array}{l}\text { Peptide } \\
\text { antigens }\end{array}$ & GM-CSF & Sunitinib & $\begin{array}{l}\text { Renal Cell } \\
\text { Carcinoma }\end{array}$ & NCT01265901 \\
\hline
\end{tabular}

US National Library of Medicine. ClinicalTrials.gov 


\section{VACCINE ADJUVANT}

Adjuvants are components in vaccines that stimulate innate immune response nonspecifically. Up to now, there are only a handful of adjuvants approved by FDA ${ }^{58}$. the Mineral components, such as aluminum salt and squalene, are common used in vaccines as they could form a "depot” to release antigens sustainably and effective for antibody induction. These adjuvants may combine with other adjuvants to enhance cellular immunity ${ }^{59}$. Among the cytokines like GM-CSF, it is preferable to added for recruiting innate immune cells in vaccines that are designed with sustained release at peripheral site $^{60}$. However, the properties with short half-life, in stability in vivo and potential possibility of inducing inflammatory of cytokine adjuvants should receive attention. On the other hand, adjuvants also functioned in immune stimulation, enhance antigen availability and regulate immune phenotype ${ }^{61-62}$, which will discuss detail in the next part. Compared with small molecules (e.g. TLR agonists) or biological agents (e.g. exosomes), nanomaterials with great adjuvancity in therapeutic cancer vaccines are more attractive due to the well stability and easy synthesis, as well as it offers a universal platform to load various antigens. However, for future clinical transformation, the detailed metabolism and excretion process should be valued.

3.1. Immune Stimulation. PAMPs (the pathogen associated molecular patterns) are effective agonists are one types of immune stimulators and most widely used in therapeutic cancer vaccine research. PAMPs derived from pathogens and could recognize PRRs (pattern recognition receptors) expressed by immune cells, achieving the regulation of downstream signaling and cytokines release ${ }^{58}$. Among the PAMPs, 
the toll-like receptors (TLR) agonists have been developed in cancer immunotherapy treatment. The small molecule TLR7/8 agonist, imidazoquinoline and derivatives are researched in various cancer model ${ }^{63}$. Activation of TLR7/8 could increase the costimulatory molecules expression and type I IFN secretion ${ }^{16}$. The bacterial outer membrane vesicles (OMVs) that have multiple bacteria-derived components including PAMPs such as lipopolysaccharide (LPS), lipoprotein, DNA, RNA, peptidoglycan, also gradually developed as cancer vaccine adjuvants ${ }^{64}$. Besides TLR agonists, the STING (stimulator of interferon genes) agonists founded in recent years have proved the strong innate DCs stimulation and type I IFN secretion. Through activate STING pathway, the natural stimulator CDN (cyclic-dinucleotides) derived from bacterial had been used as vaccine adjuvant ${ }^{65}$. However, the natural CDNs have shortage of rapid clearance, poor membrane penetration, resulting in the development of synthetic chemical compounds to stimulate STING pathway and application in therapeutic cancer vaccines ${ }^{66-67}$. Another type of immune stimulator is nanomaterial-based vaccine adjuvant. Such as cationic polymer polyethyleneimine (PEI) could stimulate pro-inflammatory cytokine release ${ }^{68}$. Through absorbed with mesoporous silica microrod (MSR) and incorporated with various antigens, the MSR-PEI offered a facial approach to enhance peptide antigen immunogenicity, exhibited great tumor eradication and inhibited tumor metastasis ${ }^{69}$. Moreover, some inorganic materials also exhibited well adjuvancity. Mesoporous silica (MS) could promote both Th1 and Th2 immune response, stimulate INF- $\gamma$, IL2 and other cytokines release as well as increase antibody titers ${ }^{70}$. Detailed inorganic nanoadjuvants was reviewed by Wang's group ${ }^{71}$. 
3.2. Nanomaterials Enhance Antigen Availability. The adjuvanticity of synthetic molecules or structures is characterized with offering vaccine delivery function and enhancing antigens delivery into lymph nodes and uptake by APCs in the meantime, further inducing antigen specific immune responsee ${ }^{72-73}$. Self-assembling peptides have been demonstrated that these may serve as vaccine adjuvants ${ }^{74-75}$. Earlier research of Collier's group proved that the self-assembling polypeptide Q11 (AcQQKFQFQFEQQ-Am) displayed well adjuvanticity when bond with tumour antigens (Figure 3). It fabricated into long, unbranched fibrils, displaying the epitope on their surface. The fibrils were originally very weak in immunogenicity, but could greatly enhance efficacy of adaptive immune response after binding with antigen peptide while mixed antigen peptides with self-assembled materials only exhibited low immunogenicity ${ }^{76}$. In addition, through replacing the self-assembled peptide sequence with KFE8 (FKFEFKFE), the Collier's group subsequently proved that the adjuvant property was independent with the self-assembled peptide sequence, but depends on the ability of fibrillation ${ }^{77}$. Further through modifying surface characteristics, the peptide assemblies were found that these self-adjuvant property is related to the surface charge $^{78}$. The peptide assemblies modified with positive charge would increase immune response while the negative surface could not induce this phenomenon. The authors demonstrated that the positive charge would increase the uptake and presentation of APCs but did not significantly affect lymphatic draining, which further contributes to the effective activation of immune response. In addition to the fibrillation of assembled peptides, the hydrogel structure also displays great adjuvant effects ${ }^{79}$. Another 
nanofibering adjuvant (self-assembled biotinylated peptide amphiphile, Biotin-PA) was found that it could induce both humoral and cellular immunity. The biotin-PA could strongly induce important cytokine release, such as IFN- $\gamma$, IL12, IL6, which directed the immunity route toward Th1 phenotype ${ }^{80}$. However, the antitumor effect in vivo was not studied. Besides, Research evaluated the vaccine adjuvant potency of both L-and D-peptide hydrogels and found that these hydrogels could increase the IgG production of ovalbumin antigen ${ }^{81-83}$. The mechanism was demonstrated as gels can also enhance antigen uptake and induce dendritic cell maturation, promote and prolong accumulation of antigen in lymph node as well as evoke germinal center formation. Moreover, the adjuvant effect of D-peptide hydrogel is better than L-type. D-peptide hydrogel could also stimulate powerful $\mathrm{CD}^{+} \mathrm{T}$ cell response and IFN- $\gamma$ secretion, inhibited tumor progression significantly, but detailed mechanism was not yet known ${ }^{84}$. To sum up, these self-adjuvant structures (fibers, hydrogels as well as nanoparticles) amplify the innate immune response activation mainly exerted by enhancing antigen uptake, presentation and the lymph node accumulation, prolong the interaction between antigens and immune cells, which eventually improved antigen specific adaptive immune response. Moreover, the cross presentation also could simultaneously achieve through smart designing in a lipid-based vaccine structure ${ }^{85}$. However, the intrinsic adjuvanticity of nanomaterials is relayed on a certain structure, which limited its development. Moreover, these adjuvanticity is mainly induced humoral immunity and is unfit for therapeutic cancer vaccines. 

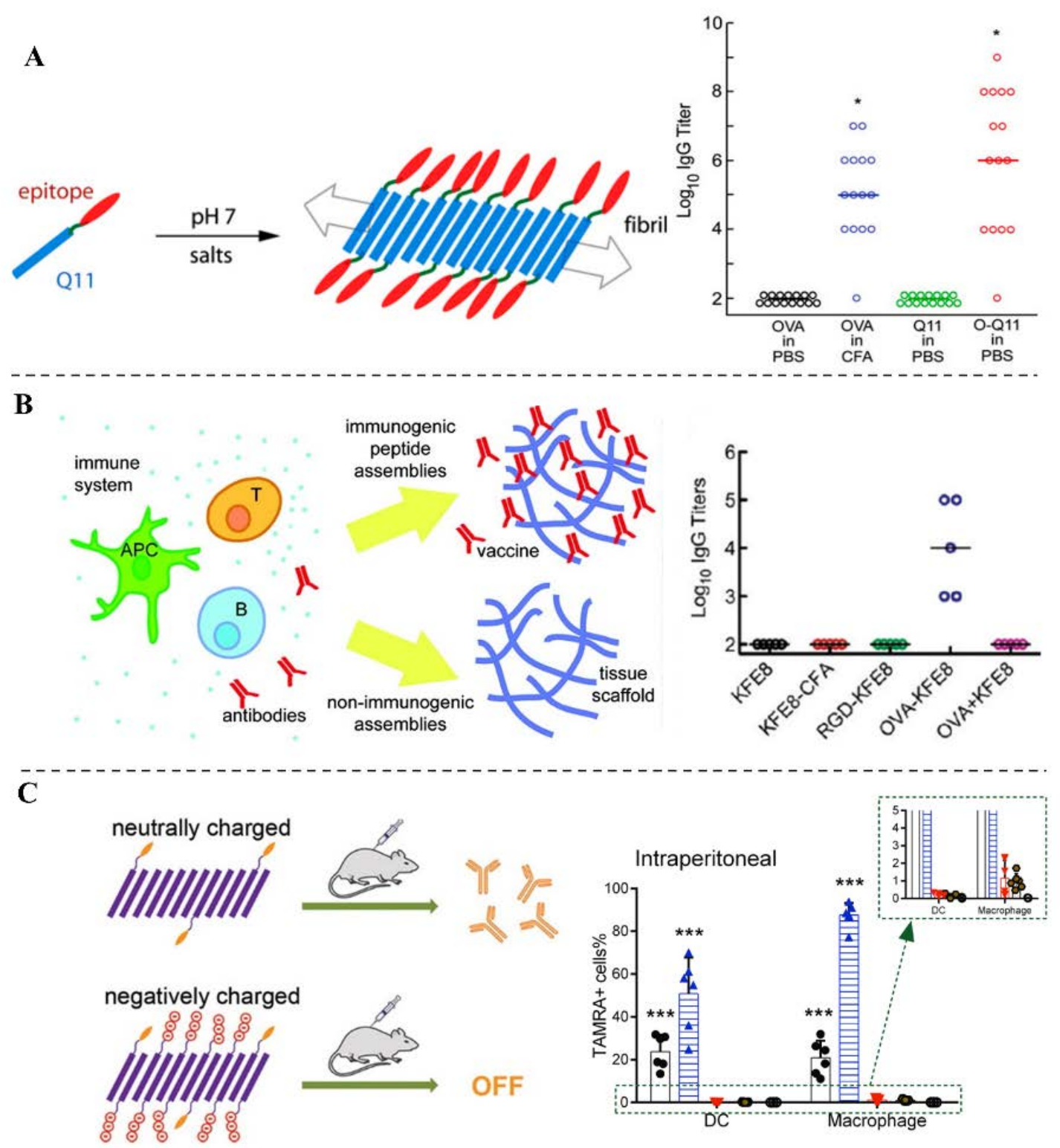

Figure 3. The peptide self-assemblies as vaccine adjuvants. (A) Fibrillization by the Q11 domain strongly adjuvanted IgG responses to OVA. Reproduced with permission from ref 76. Copyright 2010 National Academy of Sciences. (B) Immune response modulation ability of self-assembling peptides. Reproduced with permission from ref 77. Copyright 2012 American Chemical Society. (C) Immunogenicity of peptide assemblies could be switched through adjusting surface properties. Reproduced with permission from ref 78. Copyright 2016 American Chemical Society. 
3.3. Nanomaterials Regulate Immune Phenotype. Therapeutic cancer vaccines are aimed to kill tumour cells to achieve successful cancer treatment. Therefore, regulate the phenotype of immune response (Th1-mediated cellular immunity and Th2-mediated humoral immunity) is essential for therapeutic cancer vaccine therapy. The intrinsic physical properties of nanomaterials such as size and morphology have demonstrated to intervene and regulate the type of immune response. The morphology of nanomaterials influences inflammatory cytokines production, such as the sphere and cube-like carrier tend to increase TNF- $\alpha$, IL-6, IL-12 and GM-CSF while rod-like carrier prefer induce IL-1 $\beta$ and IL-18 through inflammasome-dependent pathway ${ }^{86}$. Meanwhile, the Mitragotri's group demonstrated different size and shape could induce different immune response subtype and intensity ${ }^{87}$. The small spherical particles (193 $\mathrm{nm}$ in diameter) could inducing Th1 immunity while rod shaped particles (1530 nm in length) was tend to inducing Th2 immunity. It revealed that the physicochemical properties of nanomaterials could be designed to regulate immune phenotype that is suitable for vaccines. Beside on synthetic nanomaterials, the cell-derived nanomaterials such as exosomes also used to regulate immune response ${ }^{88}$. The M1-polarized macrophages derived exosomes could home to lymph node and create a local inflammatory milieu for induction of Th1 adaptive immune response and exhibited a better effect on stimulating immune response than $\mathrm{CpG}$ oligonucleotide ${ }^{88}$. Cell-derived nanovehicles bearing distinct surface properties and components, and can mimic natural to initiate immune response, representing a new class of immune adjuvant for cancer vaccines. 


\section{THE DELIVERY SYSTEM}

The delivery of therapeutic cancer vaccines also decides the effectiveness and safety of vaccines. Biomaterials for cancer vaccines delivery has been widely studied ${ }^{89-90}$. The synthetic delivery systems were widely researched in recent years, including lipidbased delivery vehicles ${ }^{91}$, organic polymer-based delivery vehicles ${ }^{92}$, inorganic nanoparticles and other synthetic cancer vaccine delivery systems ${ }^{93}$. In addition, biological agent carrier such as bacteria and virus delivery vehicle also exhibited attractive in vaccine delivery ${ }^{94}$. The hybrid virus mainly developed in DNA-based vaccine to enhance uptake and expression. Through inserting vaccine gene into to cytomegaloviruse, the hybrid virus vaccines enhanced gene expression and antigenspecific cellular and humoral immune response ${ }^{95}$. However, hybrid virus carrier mainly researched in antibody neutralization, the cellular immunity against cancer are needed with further research ${ }^{96}$. Moreover, the smart delivery vehicles are received increasing attention. Recently, the DNA-based robotic nanostructure was reported. It offered a well-defined delivery platform based on programmable molecular systems ${ }^{97}$. As an promising vaccine delivery vehicle, it should ensure the effectively carried out in following process: antigen needs to be efficiently uptake by immature APCs, then APCs processes and presents antigens into cell surface with MHC for T cells recognition, and finally achieves $\mathrm{T}$ cell activation ${ }^{98}$. Usually, the delivery strategy is classified into three categories, the peripheral delivery and lymph node-targeting delivery, and both of them are required cytosolic delivery to enhance cross presentation. The peripheral delivery forms a "depot effect” at the peripheral site and slowly releases antigens and adjuvants, 
which is taken up by the peripheral APCs and then migrates to the lymph node to activate T cells or B cells. While the lymph note-targeting delivery is reflux vaccines to lymph node and uptake by lymph node-resident immature APCs ${ }^{14}$. Comparing with the peripheral delivery, the lymph node-targeting delivery is more favorable due to i)the inability of peripheral immature DCs (Langerhans cells) to cross present antigens, ii) The amount of immature DCs is far lower in peripheral than stored in lymph node. iii) The uptake by peripheral DCs also may lead to tolerance and T cell dysfunction ${ }^{99-100}$. Considering above reasons, delivering cancer vaccines directly to the lymph node would generate a better vaccination effect. However, the challenge is that lymph node delivery is highly dependent on vaccine hydrodynamic size ${ }^{1,14}$. The optimal hydrodynamic size is different in each vaccine delivery process ${ }^{101-104}$. Strategies to satisfy these requirements and achieve maximize use of therapeutic vaccines is to be solved (Figure 4). Moreover, cytosolic delivery of vaccine components after uptake by DCs are further discussed behind peripheral delivery and lymph node delivery. 


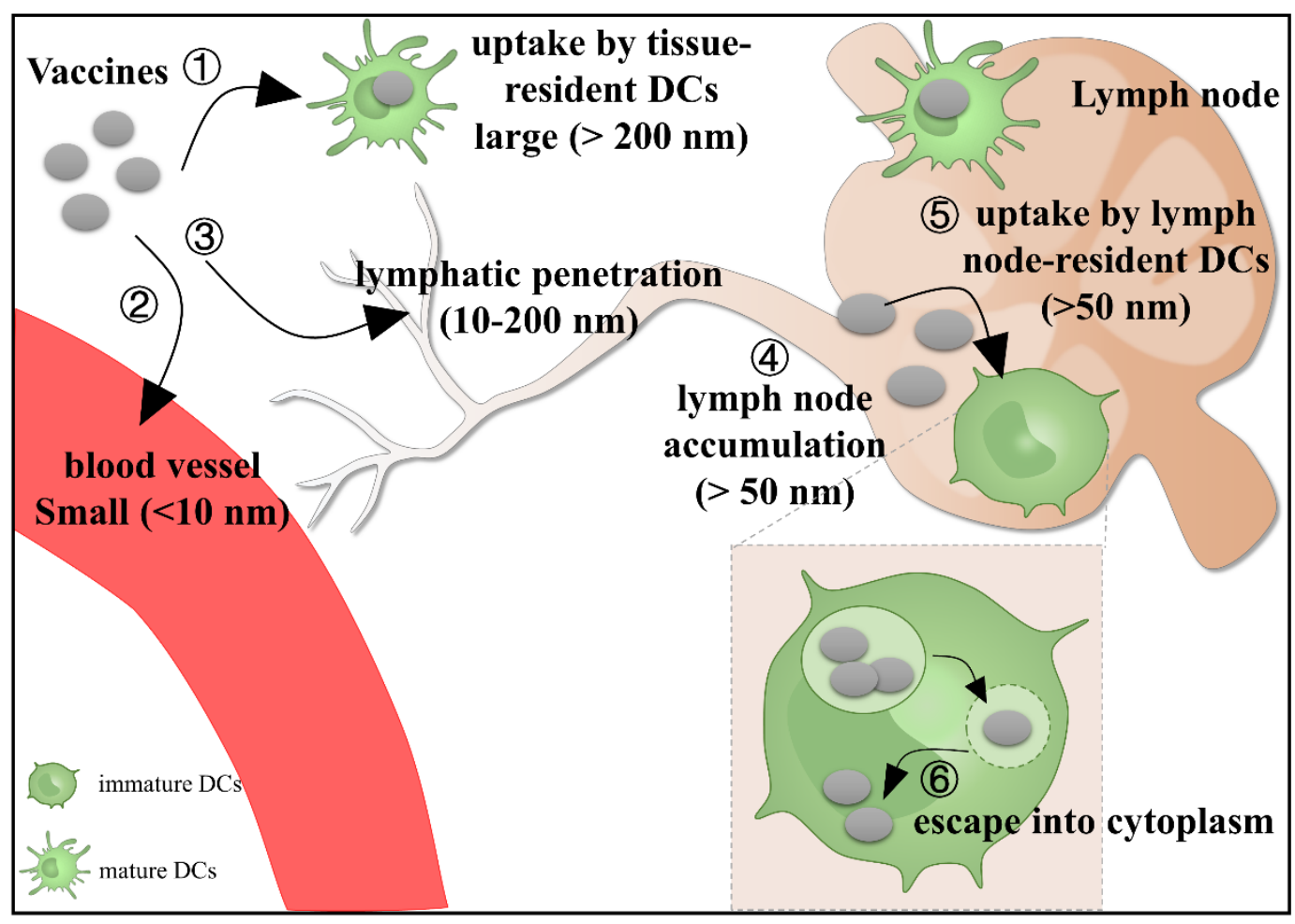

Figure 4. The cascade delivery and each hydrodynamic size requirements for therapeutic vaccines.

4.1. Peripheral delivery. The peripherally delivery is widely used in traditional vaccines. Even this strategy has been applied for a long time, there is some suboptimal aspects to be improved. The "depot effect" of alum adjuvants would lead to the degradation and metabolism over time, resulting in the under-utilization of vaccine dosage and induce side effects. Therefore, the scaffold-based cancer vaccine delivery was arising to control vaccine release $\mathrm{e}^{105-106}$. It is designed to locally release vaccine components (antigens, adjuvants and other stimulants) in a sustained or controlled manner to guarantee long time availability of components and enable to recruit dendritic cells followed by the uptake of antigens and adjuvants, then initiate innate immune response. The biodegradable scaffold allowed to release substance in a spatial 
and temporal profile, achieving a better vaccination kinetics. Moreover, multiple agents could be loaded together for a better innate immune response initiation ${ }^{105}$.

Microneedle arrays have been extensively explored as a safe and pain-free vehicle for scaffold transcutaneous delivery. Lee's group developed a smart DNA vaccine based on microneedle arrays, which continuously releases nanoengineered DNA polyplexes and adjuvant molecules over a sustained period of time. When implanted in skin (pH 7.4), the smart vaccines could transform to anionic copolymers and trigger the DNA and adjuvant release owing to electrostatic repulsion. The smart scaffold-based DNA vaccine allowed control over the physical and functional persistence of inflammatory adjuvants and vaccines ${ }^{106}$. Besides this, a clinical trial being explored for melanoma treatment (NCT01753089) development a scaffold based on PLGA with higher biocompatibility. The vaccine was contained tumour lysates as personalized cancer antigens and GM-CSF to recruit immune cells as well as vaccine adjuvant CpG. To sum up, the scaffold selected by FDA-approved materials for therapeutic cancer vaccines achieved long time releasing. The chemokine contained in scaffold further recruit dendritic cells continuously ${ }^{107}$, which is promising to translate into clinical.

4.2. Lymph Node Delivery. Multiple routes for lymph node delivery of therapeutic cancer vaccines are developed ${ }^{15}$. Intralymph node injection could significantly improve vaccine utilization ${ }^{108-109}$. Beside this, fabricate proper size of vaccine is another passive lymph node delivery strategy, which is widely used in nanomaterial-based therapeutic cancer vaccine design. In addition, modified with specific structures that could actively target lymph node also have gained attention in recent years ${ }^{14-15}$. Above all, the lymph 
node delivery of therapeutic cancer vaccines achieved a considerable reduction of antigens and adjuvants in dose and also avoid side effects to some extent, such as adjuvant-induced severe local inflammation ${ }^{58,110}$

4.2.1. Passive lymph node delivery. The passive lymph node delivery is relayed on size or directly lymph node injection to achieve vaccine components accumulated in lymph node tissue. Researches showed that through micronization, the sustainedrelease of antigen and adjuvant were successfully achieved through directly injected into lymph node ${ }^{111}$. The micronization was effectively prevented rapid clearance of vaccine components that caused by the fast flushing effect of lymph fluid and unique structural properties of lymph node and realized long time-retaining ${ }^{111}$, which further contributes to the durable activation of immune cells. However, this method requires the advance identification of lymph node location through ultrasound guidance ${ }^{112}$ or the lymph node tracking dye, Evans Blue ${ }^{113}$. This strategy seems not suitable for therapeutic cancer vaccines as it is relayed on complicated imaging techniques and tedious operation. However, lymph node delivery also could achieve by penetration from the peripheral site. Due to the special physiological structure of lymphatic vessels, vaccine carriers that efficiently penetrate into lymphatic vessels are highly depend on hydrodynamic size ${ }^{114-115}$. The high flow rate of blood stream compared with lymphatic fluid lead to the small size (below $10 \mathrm{~nm}$ ) substances are tend to enter systemic circulation and exhibited limited lymphatic uptake, while larger size ( $>200 \mathrm{~nm})$ is likely to be trapped in extracellular matrix, which also characterized with poor lymphatic uptake. A proper size is decisive for effective passive targeting of lymph node. The size 
of most nanoparticles for vaccine carrier, such as liposome, inorganic nanoparticles, are within this range $(10-200 \mathrm{~nm})$, demonstrated a good passive targeting effect ${ }^{15}$. Moreover, other considerations such as the surface charge and PEGylation could also play roles in the effect of lymph node drainage ${ }^{14}$.

4.2.2. Active Lymph Node Delivery. The effective lymph node delivery of vaccine compartments can be achieved through active targeting and draining into the lymph nodes. This strategy was relayed on ligand-receptor recognition or substance that could directly enrichment at lymph nodes. Albumin-binding strategy is a general design for improving serum stability and lymphatic distribution (Figure 5). Albumin in peripheral tissues is mainly reflux through lymphatic vessels due to the huge molecular weight (66 $\mathrm{kDa}$ ) that exceed blood circulation size range. Therefore, vaccines components modified with motifs that can bind with albumin could achieve active targeting to the lymph nodes ${ }^{116}$. The lipid motif, such as diacyl lipids ${ }^{117}, \operatorname{DSPE}^{118}$, Vitamin $^{118}$, cholesterol $^{119}$, was approved to be an optimal albumin-binding domain and could "hitchhike” to draining into lymph node. Moreover, the clinical lymph node imaging molecule, Evans blue, also was used as vaccine carrier as it could efficiently bind with albumin through hydrogen bonds ${ }^{120}$. Beside this strategy, the interstitial fluid flow also brings fragments of extracellular matrix (ECM) macromolecules, such as hyaluronic acid (HA), into lymph node. HA could also recognize its receptors on lymphatic system, CD44 or lymphatic vessel endothelial hyaluronan receptor-1 (LYVE-1). This recognition is correlated with cell to cell interactions and trafficking. Research demonstrated vaccine components conjugated with HA could facilitate targeted 
delivery to secondary lymphoid tissue while minimizing systemic exposure ${ }^{121}$. Above all, though modified with lymph node-targeting structures, it successfully achieved small-sized vaccines components efficient draining into lymph node ${ }^{122}$.

A.

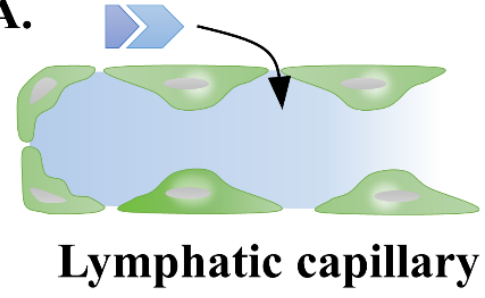

\section{Albumin}

Albumin-binding structure
B.
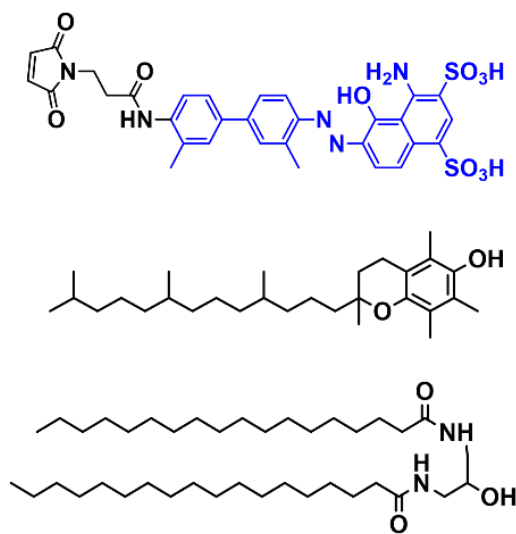

(3)

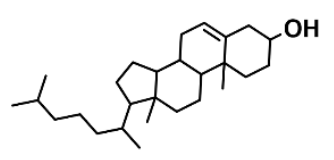

Figure 5. Active lymph node delivery strategy (A) and albumin-binding molecules (B).

4.3. Cytosolic delivery. Antigens that presented by APCs are exhibited MHC restriction. For exogenous antigens such as pathogens are presented with MHC II molecules after uptake and processing by APCs. While for endogenous antigens such as intracellular infection, are presented with MHC I molecules. Since the two presentation pathways induce activation of antibody-mediated humoral immunity and cytotoxic $\mathrm{T}$ cells mediated cellular immunity respectively, the therapeutic cancer vaccine that exhibited as exogenous antigens are expected to escape from endosome/lysosome to delivery into cytoplasm as much as possible, thus inducing cellular immunity through cross presentation ${ }^{123}$. Therefore, how to effectively deliver the antigens to the cytoplasm of dendritic cells is a key step, especially for RNA vaccines that need to translate at cytoplasm ${ }^{124-125}$. The cytoplasm delivery needs 
vaccines rapidly escape from phagosome/lysosome in dendritic cells, which required vaccines remained integrity at physiological environment until enter into phagosome/lysosome compartment. The triggering factors such as $\mathrm{pH}^{126}$, redox ${ }^{127}$ or external stimuli ${ }^{128}$, could lead to lysosome breakage and antigen leakage ${ }^{129}$. For example, through coencapsulated with cancer antigen (ovalbumin, OVA), the $\mathrm{pH}$ responsive poly(D,L-lactic-co-glycolic acid) (PLEA) NPs containing ammonium bicarbonate $\left(\mathrm{NH}_{4} \mathrm{HCO}_{3}\right)$ could react with hydrogen ions $\left(\mathrm{H}^{+}\right)$in DC endosomes/lysosomes that exhibited low $\mathrm{pH}$ (5.0-6.5), and generated $\mathrm{NH}_{3}$ and $\mathrm{CO}_{2}$ to broke NPs and released antigens. This process also inducing NPs and antigens escape from lysosomes into the cytoplasm, finally promoting cancer vaccines cytosolic delivery ${ }^{126}$. In another study, antigens conjugated with carriers through disulphide bond could further inducing antigens release and escape in GSH-containing endosomelysosome. The redox-triggered release of surface modified antigens could be designed to open channels for protons flow when combined with proton pump effect-induced materials and induce amplified cytosol delivery ${ }^{130}$. In addition to intracellular microenvironment response, the autophagy pathway also contributes to antigen cross presentation (Figure 6). Antigens escape from lysosome and initiated autophagy process by combining with autophagy-inducing peptide (Beclin 1). The results demonstrated that upregulating autophagy in dendritic cells lead to effectively antigen cross presentation and cytotoxic $\mathrm{T}$ cells activation. In this work, the $\mathrm{pH}$ responsive nanocarrier promotes the endosomal escape and further induce autophagy and activate immune response with a lower dose and without significant cytotoxicity. The precise 
control to the dosage of autophagy-inducing peptide was required to optimize the vaccine therapeutic efficacy ${ }^{131}$.

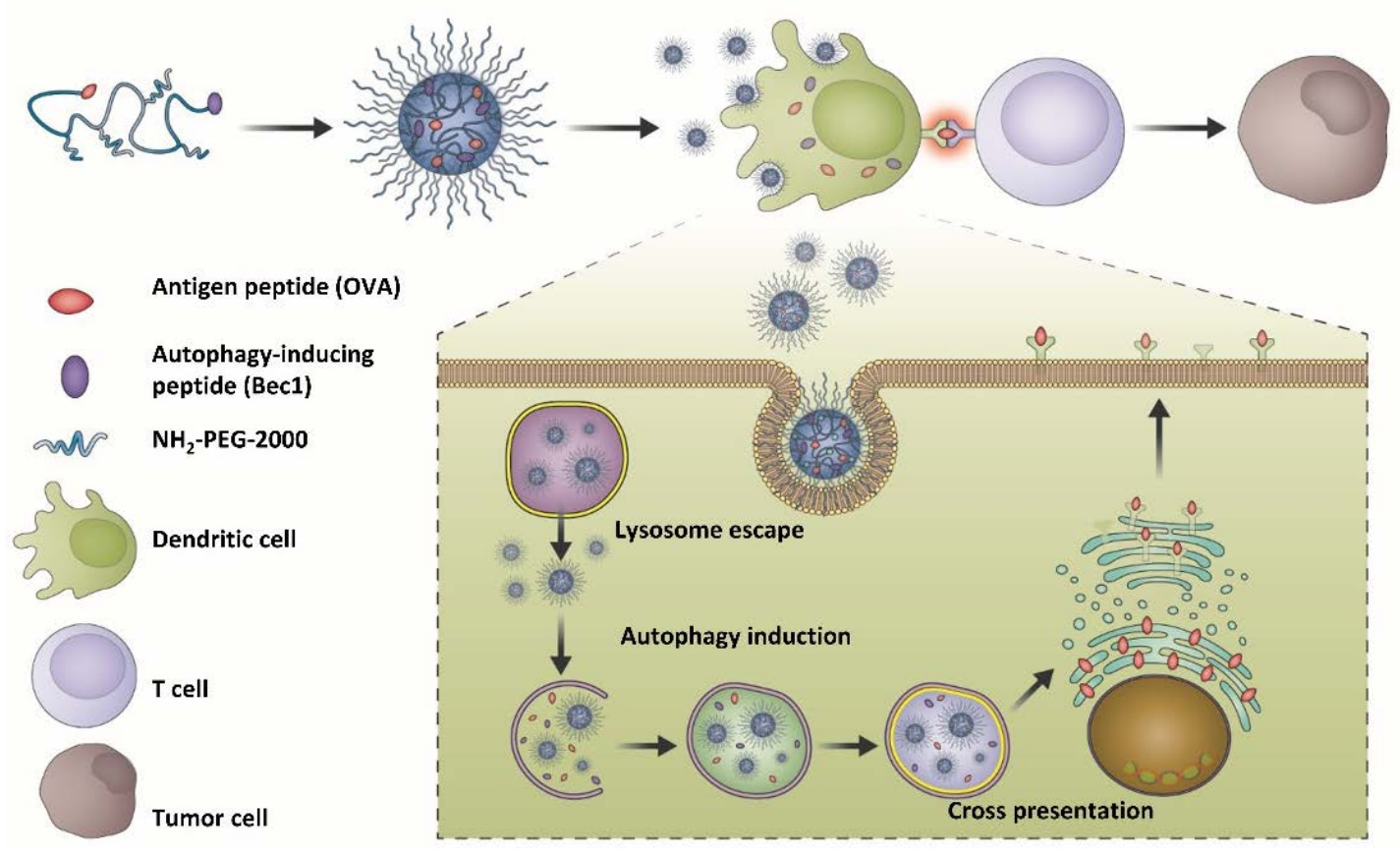

Figure 6. Schematic of nanoactivtor inducing autophagy for cross-presentation and priming T cells. Reproduced with permission from ref 131. Copyright 2019 American Chemical Society.

The delivery of therapeutic cancer vaccines highly influences vaccine efficacy and safety. Each strategy owed their inherent advantages, since the cascade delivery process (lymphatic penetration and accumulation, uptake by dendritic cells, release into cytoplasm) acquired individually requirements, how to optimal satisfy those requirements and maximize the use of vaccine are still need further consideration.

\section{COMBINATION WITH THERAPEUTIC CANCER VACCINE}

Tumour immunosuppressive environment significantly limits the efficacy of cancer immunotherapy though supporting tumour cells growth, metastatic and attenuating of immune surveillance ${ }^{19-20}$. There are multiple mechanisms assisting cancer cells to 
evade and destruct the anti-tumour immune response, such as recruiting myeloidderived suppressor cell (MDSC), promoting the polarization of tumour associated macrophage (TAM) to M2 phenotype, as well as controlling the tumour resident T cells to be an exhausted state through expressing inhibitory receptors such as programmed cell death-ligand 1 (PD-L1), lymphocyte activation gene 3 protein (LAG-3), T cell immunoglobulin-3 (TIM-3), which finally lead to the limited anti-tumour efficacy ${ }^{132}$. The complicated tumour immunosuppressive environment seriously impacts the function of therapeutic cancer vaccines (Figure 7). Therefore, combination with other strategies are developed to improve anti-tumour effects ${ }^{17,133}$.

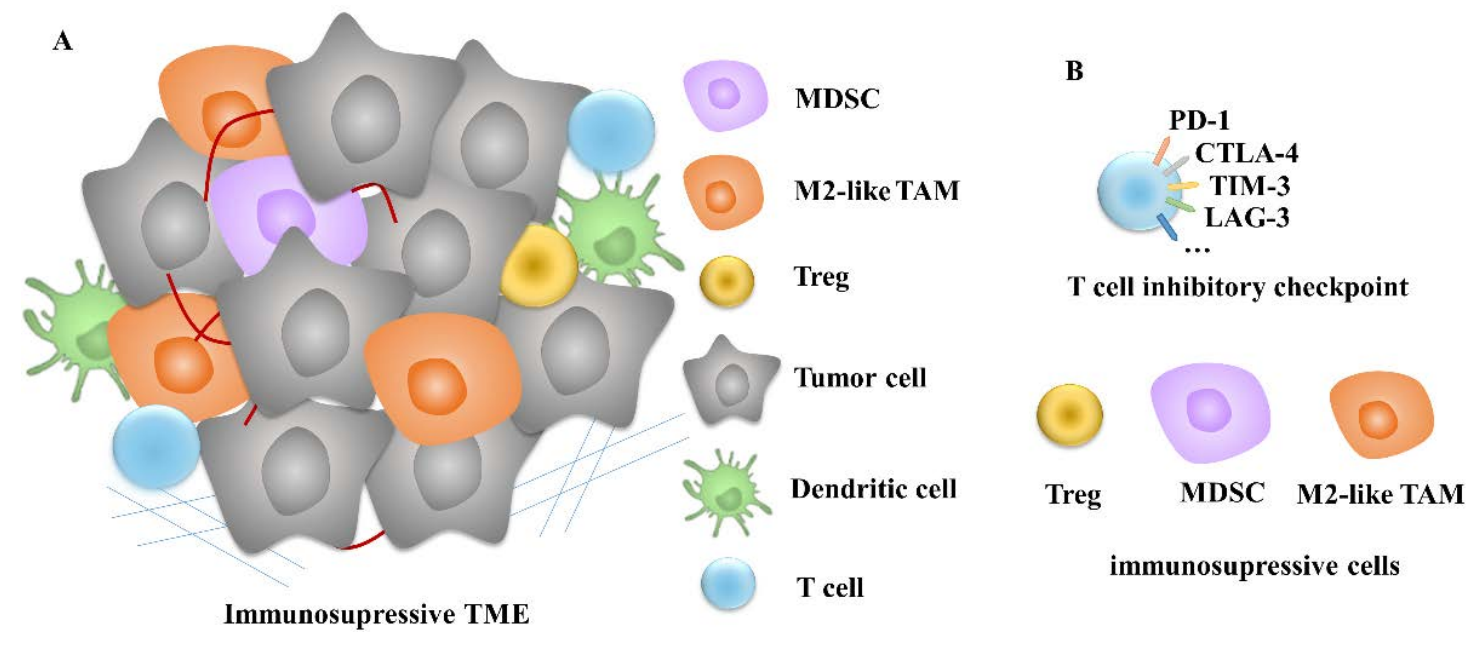

Figure 7. Schematic illustration of immunosuppressive environment of tumour (A). (B)

$\mathrm{T}$ cell inhibitory checkpoints and immunosupressive cells in tumour.

5.1. Combination with Immune Checkpoint Blockade. Tumour cells suppress $T$ cell function through multiple immune checkpoints and the immune checkpoint blockade (ICB) antibody has been regarded as one of the most successful methods in cancer treatment in combination with other immunotherapy ${ }^{134}$. Multiple immune checkpoint blocking antibodies have been approved by FDA. Such as lpilimumab for 
CTLA-4 blockade in melanoma, Pembrolizumab and Nivolumab for PD-1 blockade in non-small cell lung cancer (NSCLC), melanoma and other certain tumours, as well as Atezolizumab for PD-L1 blockade in NSCLC ${ }^{135}$. A phase I clinical research showed the combination of anti-CTLA-4 antibody with allogeneic pancreatic tumour cells based vaccine that transfected with a GM-CSF gene (GVAX) was been evaluated in pancreatic ductal adenocarcinoma (PDA) patients. The results showed a prolonged disease stabilization ${ }^{136}$. In another study, the CTLA-4 blockading antibody combined with synthetic cancer therapeutic vaccine for triple negative breast cancer (TNBC) ${ }^{137}$. The research found that vaccine-induced T cell activation through TCR and CD28 on T cell surface would lead to increase expression of CTLA-4 and eventually attenuates and terminates $\mathrm{T}$ cell responses. Through combination with anti-CTLA-4 antibody, the therapeutic effects of the vaccine on TNBC were greatly enhanced. Moreover, the improved $\mathrm{T}$ cell infiltration in tumour tissue was observed that further contributes to the effective blockade of the CTLA-4 pathway ${ }^{138}$. Moreover, the PD-L1 bind with PD1 expressed in $\mathrm{T}$ cells would lead to the $\mathrm{T}$ cells apoptosis through various mechamisms ${ }^{116}$. Combination with PD-1/PD-L1 blockade therapy would also combat immune resistance and enhance antitumour T cells efficacy. Through constructing a personalized cancer vaccine combined with PD-L1 inhibition, it demonstrated the efficacy of the combination on post-surgical immunotherapy to prevent of tumour recurrent and metastasis ${ }^{53}$. In addition, in a phase II clinical trial (NCT02426892), the therapeutic HPV vaccines, a synthetic long-peptide HPV-16 vaccine could induce HPV-specific T cells response, produce strong immune responses against HPV-16 
combined with anti-PD-1 antibody, but vaccination alone showed limited efficacy for invasive cancer. Moreover, blocking PD-1 also plays roles in reducing Foxp3(+) regulatory T cells (Treg) and increasing of IFN- $\gamma$ secreted CD8+ T cells when combined with whole-tumour cell antigen ${ }^{139}$.

Above all, the combination between therapeutic cancer vaccines and immune checkpoint blockade therapy played a synergy effect ${ }^{140}$. However, a large number of unresponsive cases have occurred in clinical applications may influence the combination effect. Therefore, the evaluation of whether patient is response to ICB and reasonable combination with multiple immune checkpoint blockade strategies need further consideration.

5.2. Chemotherapy Combination. The chemotherapeutic agents induce tumour regression by cell cytotoxicity. For the cancer immunotherapy, the chemotherapy was designed to induce the ICD of targeted tumour cells, which further produce mixed tumour antigens in vivo, also presented variety immune stimulatory molecules. In addition, researches showed that low dose of certain chemotherapeutics (e.g. paclitaxel $^{141}$, Gemcitabine ${ }^{142-143}$, cyclophosphamide ${ }^{144-145}$ ) could selectively modulate immunosuppressive cells and reprogram immune tolerance in TME. Therefore, the cancer vaccines could combine with chemotherapeutic drugs to achieve an improved vaccine efficacy. Cyclophosphamide (CY), is a traditional cytotoxic cancer drug that damage DNA and also contribute to antitumour immunity. Mechanisms revealed that single administration of low dose CY prior to dendritic cell vaccination of tumourbearing mice, which further contributes to the enhanced anti-tumour immune response 
through depleting Treg cells and increase the secretion of immunostimulatory cytokines, such as IFN- $\gamma^{146}$. Moreover, it was found that CY could selectively targeting Treg cells due to the relatively low levels of ATP in Treg cells ${ }^{146}$. ATP is involved in the synthesis of glutathione, which offers a detoxification method through combined with active phosphoramide mustard. Thus, the reduced ATP could not efficiently detoxify $\mathrm{CY}^{146}$. Moreover, though combined with GM-CSF modified tumour vaccine and paclitaxel, it was further demonstrated that the dose and administration sequence of paclitaxel highly influence vaccine-induced tumour regression. It was proved that low-dose paclitaxel mainly enhances the anti-tumour immune response at the priming time, which suggests the pre-vaccine paclitaxel administration is more potent than post-vaccine paclitaxel ${ }^{141}$. Therefore, the ideal time window after chemotherapeutics administration also need to take into account when combined with cancer therapeutic vaccines.

5.3. Radiation Therapy Combination. The radiation therapy (RT) has become one of the most important strategy for cancer treatment. It used for solid tumours that are too extensive to be surgically resected. Similar with chemotherapy, the application of radiation therapy also could induce DNA damage and fragments production from dying tumour cells, which further stimulate STING pathway and type I IFN production and enhance anti-tumour immune response. The local radiation could minimize or eradicate metastases at distant sites that is not irradiated, this phenomenon is called the "abscopal effect” and is found clinically in various cancers and frequently occurs in combination with immunotherapy ${ }^{147}$ (Figure 8). It was supposed that the radiation could induce various cytokines secreted into blood circulation and regulate immune cells combined 
with immunotherapy, which finally lead to minimize or eradicate distant metastases ${ }^{147-}$ ${ }^{149}$. Through smart cascade designing, Morris’ group developed a bacterial membranecoated nanoparticle (BNP) for in situ vaccination, which further combined with RT for better activation of immune response. The BNP consisted four components, polyplex that facilitates the endosomal escape, CpG for TLR-9 activation, bacterial membrane and modified maleimide groups on surface to enhance antigen uptake. Through intratumoural injected after radiation, it could capture neoantigens released by RT, subsequently uptake by dendritic cells and activate innate immune response. The cascade reaction of BNP combined with RT showed significant tumour regression and tumour-specific antitumour immune memory ${ }^{150}$. However, the limitation of RT in immunotherapy is that it could induce immunosuppressive cytokines release, such as TGF- $\beta$, which is assisted to the tumour evasion, metastasis and the high level expression of PD-L1 ${ }^{151}$. Therefore, further combined with other immunotherapy may achieve a better anti-tumour effect. 


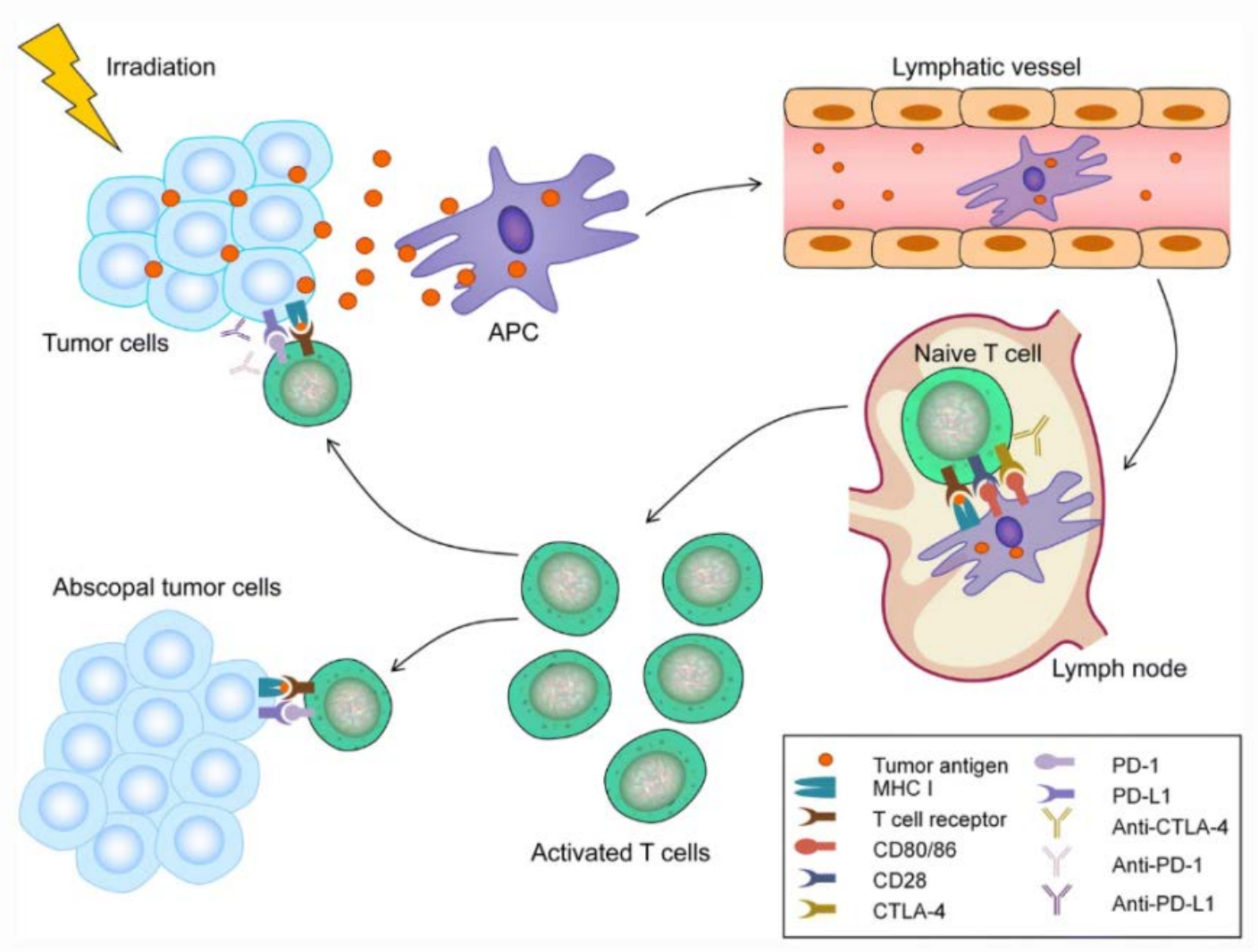

Figure 8. Mechanism of the abscopal effect in radiation therapy. Reproduced with permission from ref 147. Copyright 2018 Springer Nature.

5.4. Antiangiogenic Treatments Combinations. In addition to regulate immunosuppressive cells, targeting tumour microenvironment to reprogram the function of immune cells provide another way for cancer vaccine combination therapy. Angiogenesis in tumour tissue play essential roles in tumour growth and metastasis. Dysfunction of tumour vasculature is highly related with acidity, hypoperfusion, hypoxia and high pressure environment, which finally influence immune cells infiltration and function ${ }^{152}$. Moreover, the hypoxia is highly related with polarize TAMs to immunosuppressive phenotype and lead to more proangiogenic cytokine (VEGF) release that would further induce severe abnormal of tumour vasculature ${ }^{151}$. Therefore, the combination of cancer therapeutic vaccine with antiangiogenic strategy could be 
implemented under various mechanisms. Combining antiangiogenic tyrosine kinase inhibitors (TKI) with recombined virus vaccines containing costimulatory molecules and carcinoembryonic antigen genes, it improves antitumour activity by inducing vascular normalization and lead to decreased tumour-cell density, consequently induce an improvement in vascular perfusion and oxygenation ${ }^{153}$. In addition, research further studied the different doses of an anti-VEGF receptor 2 (VEGFR2) antibody treatment effects (Figure 9). It showed that only the lower doses $(10 \mathrm{mg} / \mathrm{kg})$ of anti-VEGFR2 therapy could reprogram the tumour microenvironment away from immunosuppression toward potentiation of cancer vaccine therapies. While higher dose (40 mg/kg) failed to induce TAM to M1-like polarization and restricted the infiltration of effector T cells into tumour parenchyma, leading to the impaired cancer vaccine therapy ${ }^{154}$. On the other hand, targeting endothelial cells (ECs) lining the tumour vasculature demonstrated also attractive to prevent solid tumour growth. In this method, the therapeutic antigens are derived from endothelial cells and can act as universal cancer vaccines. Evidence demonstrated that the endoglin, a proliferation-associated antigens expressed on endothelial cells, is upregulated in tumour vasculature. Through recombined extracellular domain of porcine endoglin as xenogeneic protein vaccine, the study proved that it could induce antiangiogenic effects in several mouse tumour models. Further combined with low-dose cisplatin, it achieved superior antitumour activities ${ }^{155}$. However, it may lead to autoimmune vasculitis due to the endothelialrelated antigens also expressed in normal tissues. Compared with immune inhibit signals on cancer cells, the tumour endothelium-based cancer vaccine seems offering 
another strategy for immunotherapy combination. The key challenge based on this method is to precise select tumour vasculature-associated antigens not normal tissue vasculature-associated antigens to avoid sever side effects ${ }^{156}$.

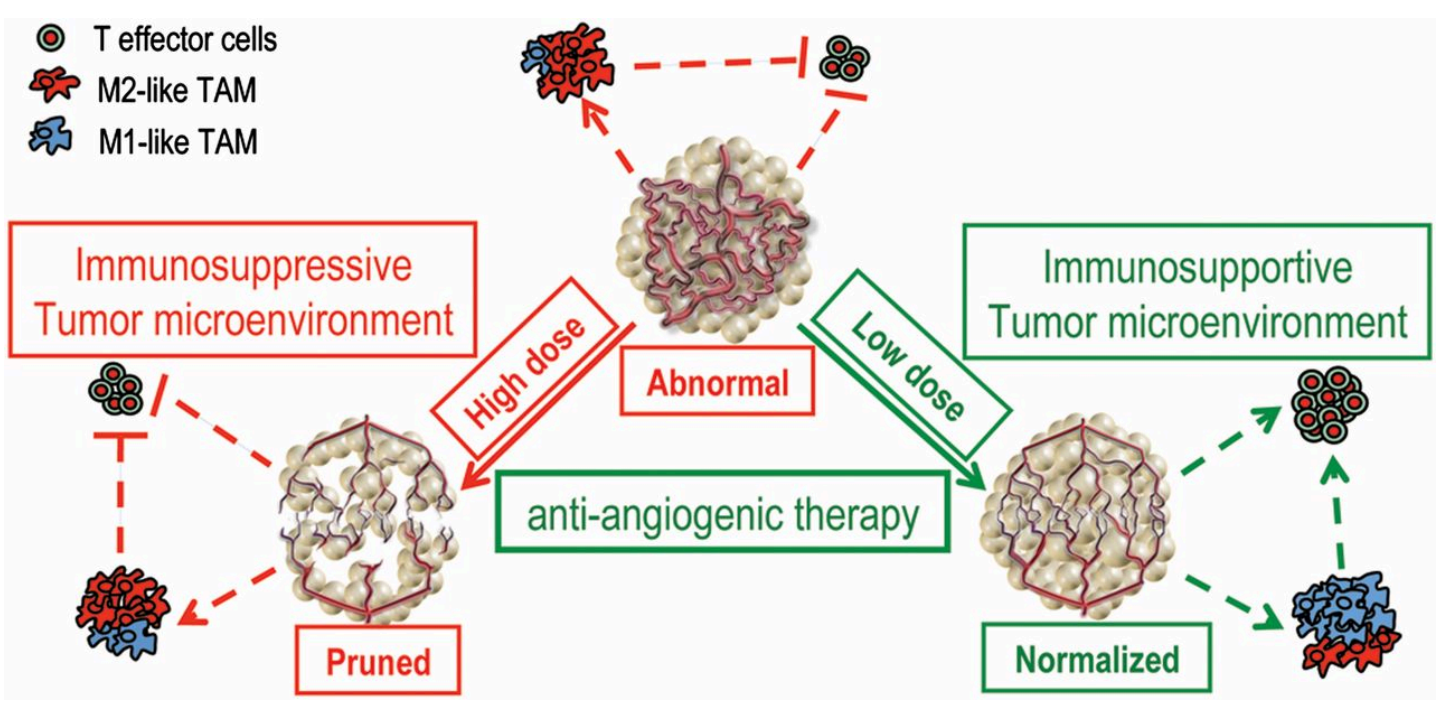

Figure 9. Schematic for vascular normalizing doses of antiangiogenic treatment reprogram the immunosuppressive tumour microenvironment. Reproduced with permission from ref 154. Copyright 2012 National Academy of Sciences.

5.5. Combination with Immune Evasion Inhibitory. Multiple mechanisms are concluded for tumour cells escape from immune evasion, including avoid immune recognition and elimination, as well as create immune suppressive environment ${ }^{3,157}$. Among this mechanisms, the CD47-SIRP- $\alpha$ interaction was widely researched. Tumour calls express CD47, which ligand is signal-regulatory protein- $\alpha$ (SIRP- $\alpha$ ) expressed by myeloid cells, including macrophages. The CD47-SIRP- $\alpha$ axis serve as an “don’t eat me” signal help tumour cells escape from phagocytosis by macrophage. Blocking CD47-SIRP- $\alpha$ signal axis combined with colony stimulating factor 1 receptor (CSF-1) inhibitor could enhances M2-to-M1 repolarization within the tumour microenvironment ${ }^{158}$. A SIRP- $\alpha$ variants harboring exosome was demonstrated it could 
sufficiently enhance tumour phagocytosis and relate with significant tumour inhibition ${ }^{159}$. However, CD47 is also widely expressed on normal cells as cell-surface antigen, thus, there is an obstacle for antibody to block CD47 as it will cause systemic toxicity. Some researchers further explored the vaccination with CD47-deficient tumour cells or tumour antigen-carrying normal cells and achieved promising results in both mouse melanoma and lymphoma models ${ }^{160-161}$. Moreover, photosensitizer paused dendritic cells or tumour cells combined with photodynamic therapy (PDT) was also proved the potential to be used as an effective cancer vaccine, as it could induce ROSbased oxidative stress, which further cause dysregulation of DAMPs and CD47 on the surface of tumour cells ${ }^{162}$. However, the tumour environment is an intricate network to escape immune evasion and the limited efficacy in single-modality of clinical vaccination therapy, it necessary of combined-modality with vaccination to facelifted vaccine-induced antitumour immune response ${ }^{163}$.

\section{CONCLUSION AND PERSPECTIVE}

In this review, we have summarized the current status of therapeutic cancer vaccines. With the promising results in fundamental research and clinical trials, the therapeutic cancer vaccines are exerting as growing important part in cancer immunotherapy. Despite this, there are some limitations urgently need to be considered. As we discussed above, the tumour antigens, vaccine adjuvants, the delivery systems and combination strategies, each step has its own unsolved challenges that dissatisfied therapeutic vaccine efficacy. 
Insufficient immunogenicity and tumour heterogeneity are major obstacles for tumour antigens development. Adequate immunogenicity is the primary factor for therapeutic vaccine efficacy and insufficient immunogenicity would lead to selftolerance of tumour antigen. Although the specific tumour antigens are hopeful to resolve those two obstacles, the complicated identification technique may impede its development. In contrast, the autologous tumour antigen-based cancer vaccine seems more feasible in clinical application. Moreover, since the chemotherapy and radiation could release autologous antigens and immunostimulants, how to efficiently utilized those components also should be valued.

For therapeutic vaccine delivery, challenges to maximize satisfy these requirements have to be emphasized, such as the lower size of delivery system is required to enhance lymphatic penetration while higher size is expected to improve lymph node accumulation and dendritic cells uptake, as well as the additional designs to escape from endosome/lysosome.

The challenges for cancer vaccines adjuvants are existed in many aspects. Not only the limited adjuvants approved by FDA and available limitation for cancer vaccines, also with the unclear mechanism for most approved adjuvants, as well as the poor safety, all these challenges further impede cancer vaccine development. Novel nanomaterials have demonstrated its adjuvanticity for therapeutic cancer vaccines. However, most of them are functioned through enhancing antigen availability. The detailed mechanisms and novel immunostimulatory nanomaterials or substance with good safety are need to be further researched. 
Last, the efficacy of antitumour immune response produced by therapeutic cancer vaccines are heavily impacted by tumour immunosuppressive environment, which composed of various suppressive immune cells, signal pathways, cytokines, as well as the own inhibitory mechanisms by tumour cells. The various combination strategies are exhibited promising results in resisting the complicated immunosuppressive environment. However, we are still not fully understood the detailed mechanisms of immunosuppression and immune escape, which is hindered the optimal design of combination strategies with therapeutic cancer vaccines. Moreover, the complicated immunosuppressive pathway network may further ask multiple strategies combined to achieve successful anti-tumour immunity. The effective and rational combination strategies while guaranteed the safety is required more consideration.

Above all, the encouraging clinical results of therapeutic cancer vaccines exhibited great promise for cancer treatment, especially with the development of personalized cancer vaccines. With the innovation of technology and optimized vaccine design, we believe the therapeutic cancer vaccines will be a notable milestone of personalized therapy in cancer treatment.

\section{AUTHOR INFORMATION}

\section{Corresponding Author}

Email: wanghao@nanoctr.cn (H. W.)

\section{Present Addresses}


CAS Center for Excellence in Nanoscience, CAS Key Laboratory for Biomedical Effects of Nanomaterials and Nanosafety, National Center for Nanoscience and Technology (NCNST), Beijing 100190, P.R. China; Center of Materials Science and Optoelectronics Engineering, University of Chinese Academy of Sciences, Beijing 100049, P.R. China; orcid.org/0000-0002-1961-0787.

\section{Author Contributions}

H.W. conceived the project. J.W. wrote the manuscript and M.M. helped for discussion and language editing. The manuscript was written through the contributions of all authors. All authors have given approval to the final version of the manuscript.

\section{Funding Sources}

Financial support from the National Key R\&D Program of China (2018YFE0205400), the National Natural Science Foundation of China (51725302, 11621505, and 51890894), the Strategic Priority Research Program of Chinese Academy of Sciences (XDB36000000) are acknowledged.

\section{Notes}

The authors declare no competing financial interest.

\section{ACKNOWLEDGMENT}

The authors sincerely acknowledge Dr. Hong-wei An (CAS Key Laboratory for Biological Effects of Nanomaterials and Nanosafety, National Center for Nanoscience and Technology (NCNST)) for kindly suggestions on manuscript frame structure. 


\section{REFERENCES}

(1) Melief, C. J. M.; van Hall, T.; Arens, R.; Ossendorp, F.; van der Burg, S. H., Therapeutic cancer vaccines. J. Clin. Investig. 2015, 125, 3401-3412. DOI: 10.1172/JCI80009

(2) Tran, T.; Blanc, C.; Granier, C.; Saldmann, A.; Tanchot, C.; Tartour, E., Therapeutic cancer vaccine: building the future from lessons of the past. Semin Immunopathol 2019, 41, 69-85. DOI: 10.1007/s00281-018-0691-z

(3) van der Burg, S. H.; Arens, R.; Ossendorp, F.; van Hall, T.; Melief, A. J. M., Vaccines for established cancer: overcoming the challenges posed by immune evasion. Nat. Rev. Cancer 2016, 16, 219-233. DOI: 10.1038/nrc.2016.16

(4) Ju, H.; Xing, W.; Yang, J.; Zheng, Y.; Jia, X.; Zhang, B.; Ren, H., An effective cytokine adjuvant vaccine induces autologous $\mathrm{T}$-cell response against colon cancer in an animal model. BMC Immunol 2016, 17, 31. DOI: 10.1186/s12865-016-0172-x

(5) McCarthy, E. F., The toxins of William B. Coley and the treatment of bone and soft-tissue sarcomas. Iowa Orthop J 2006, 26, 154-158.

(6) Decker, W. K.; Safdar, A., Bioimmunoadjuvants for the treatment of neoplastic and infectious disease: Coley's legacy revisited. Cytokine Growth Factor Rev. 2009, 20, 271-281. DOI: 10.1016/j.cytogfr.2009.07.004

(7) Finn, O. J., The dawn of vaccines for cancer prevention. Nat. Rev. Immunol. 2018, 18, 183-194. DOI: 10.1038/nri.2017.140

(8) Melero, I.; Gaudemack, G.; Gerritsen, W.; Huber, C.; Parmiani, G.; Scholl, S.; Thatcher, N.; Wagstaff, J.; Zielinski, C.; Faulkner, I.; Mellstedt, H., Therapeutic vaccines for cancer: an overview of clinical trials. Nat Rev Clin Oncol 2014, 11, 509524. DOI: 10.1038/nrclinonc.2014.111

(9) van der Burg, S. H., Correlates of immune and clinical activity of novel cancer vaccines. Semin.Immunol. 2018, 39, 119-136. DOI: 10.1016/j.smim.2018.04.001

(10) Vermaelen, K., Vaccine Strategies to Improve Anti-cancer Cellular Immune Responses. Front.Immunol. 2019, 10. 8. DOI: 10.3389/fimmu.2019.00008

(11) Schumacher, T. N.; Schreiber, R. D., Neoantigens in cancer immunotherapy. Science 2015, 348, 69-74. DOI: 10.1126/science.aaa4971

(12) Zhao, W.; Wu, J.; Chen, S.; Zhou, Z., Shared neoantigens: ideal targets for offthe-shelf cancer immunotherapy. Pharmacogenomics 2020, 21, 637-645 DOI: 10.2217/pgs-2019-0184

(13) Gubin, M. M.; Artyomov, M. N.; Mardis, E. R.; Schreiber, R. D., Tumor neoantigens: building a framework for personalized cancer immunotherapy. J. Clin. Investig. 2015, 125, 3413-3421. DOI: 10.1172/JCI80008

(14) Jiang, H.; Wang, Q.; Sun, X., Lymph node targeting strategies to improve vaccination efficacy. $J$ Control Release 2017, 267, 47-56. DOI: 10.1016/j.jconrel.2017.08.009

(15) Moyer, T. J.; Zmolek, A. C.; Irvine, D. J., Beyond antigens and adjuvants: formulating future vaccines. J. Clin. Investig. 2016, 126, 799-808. DOI: 10.1172/JCI81083 
(16) Coffman, R. L.; Sher, A.; Seder, R. A., Vaccine Adjuvants: Putting Innate Immunity to Work. Immunity 2010, 33, 492-503. DOI: 10.1016/j.immuni.2010.10.002 (17) Predina, J.; Eruslanov, E.; Judy, B.; Kapoor, V.; Cheng, G.; Wang, L.-C.; Sun, J.; Moon, E. K.; Fridlender, Z. G.; Albelda, S.; Singhal, S., Changes in the local tumor microenvironment in recurrent cancers may explain the failure of vaccines after surgery. Proc. Natl. Acad. Sci. U.S.A. 2013, 110, E415-E424. DOI: 10.1073/pnas.1211850110 (18) Polak, M. E.; Borthwick, N. J.; Jager, M. J.; Cree, I. A., Melanoma vaccines: The problems of local immunosuppression. Hum.Immunol. 2009, 70, 331-339. DOI: 10.1016/j.humimm.2009.01.017

(19) Pitt, J. M.; Marabelle, A.; Eggermont, A.; Soria, J. C.; Kroemer, G.; Zitvogel, L., Targeting the tumor microenvironment: removing obstruction to anticancer immune responses and immunotherapy. Ann. Oncol. 2016, 27, 1482-1492. DOI: 10.1093/annonc/mdw168

(20) Joyce, J. A.; Fearon, D. T., T cell exclusion, immune privilege, and the tumor microenvironment. Science 2015, 348, 74-80. DOI: 10.1126/science.aaa6204

(21) Hollingsworth, R. E.; Jansen, K., Turning the corner on therapeutic cancer vaccines. NPJ Vaccines 2019, 4. DOI: 10.1038/s41541-019-0103-y

(22) Guo, C.; Manjili, M. H.; Subjeck, J. R.; Sarkar, D.; Fisher, P. B.; Wang, X.-Y., Therapeutic Cancer Vaccines: Past, Present, and Future. In Advances in Cancer Research, Vol 119, Tew, K. D.; Fisher, P. B., Eds. 2013; Vol. 119, pp 421-475. DOI: 10.1016/B978-0-12-407190-2.00007-1

(23) Schumacher, T. N.; Scheper, W.; Kvistborg, P., Cancer Neoantigens. In Annual Review of Immunology, Vol 37, 2019, Yokoyama, W. M., Ed. 2019; Vol. 37, pp 173200. DOI: 10.1146/annurev-immunol-042617-053402

(24) Tardon, M. C.; Allard, M.; Dutoit, V.; Dietrich, P.-Y.; Walker, P. R., Peptides as cancer vaccines. Curr Opin Pharmacol 2019, 47, 20-26. DOI: 10.1016/j.coph.2019.01.007

(25) Malonis, R. J.; Lai, J. R.; Vergnolle, O., Peptide-Based Vaccines: Current Progress and Future Challenges. Chem. Rev. 2020, 120, 3210-3229. DOI: 10.1021/acs.chemrev.9b00472

(26) Kalariya, M.; Ganta, S.; Amiji, M., Multi-Compartmental Vaccine Delivery System for Enhanced Immune Response to gp100 Peptide Antigen in Melanoma Immunotherapy. Pharm. Res. 2012, 29, 3393-3403. DOI: 10.1007/s11095-012-0834-1 (27) Sexton, A.; Whitney, P. G.; Chong, S.-F.; Zelikin, A. N.; Johnston, A. P. R.; De Rose, R.; Brooks, A. G.; Caruso, F.; Kent, S. J., A Protective Vaccine Delivery System for In Vivo T Cell Stimulation Using Nanoengineered Polymer Hydrogel Capsules. Acs Nano 2009, 3, 3391-3400. DOI: 10.1021/nn900715g

(28) Huang, Z.-H.; Shi, L.; Ma, J.-W.; Sun, Z.-Y.; Cai, H.; Chen, Y.-X.; Zhao, Y.-F.; Li, Y.-M., a Totally Synthetic, Self-Assembling, Adjuvant-Free MUC1 Glycopeptide Vaccine for Cancer Therapy. J. Am. Chem. Soc. 2012, 134, 8730-8733. DOI: 10.1021/ja211725s

(29) Melief, C. J. M.; van der Burg, S. H., Immunotherapy of established (pre) malignant disease by synthetic long peptide vaccines. Nat. Rev. Cancer 2008, 8, 351360. DOI: $10.1038 / \mathrm{nrc} 2373$ 
(30) Corradin, G.; Kajava, A. V.; Verdini, A., Long Synthetic Peptides for the Production of Vaccines and Drugs: A Technological Platform Coming of Age. Sci Transl Med 2010, 2, 50rv3. DOI: 10.1126/scitranslmed.3001387

(31) Kirner, A.; Mayer-Mokler, A.; Reinhardt, C., IMA901: A multi-peptide cancer vaccine for treatment of renal cell cancer. Hum Vaccin Immunother 2014, 10, 31793189. DOI: 10.4161/21645515.2014.983857

(32) McNamara, M. A.; Nair, S. K.; Holl, E. K., RNA-Based Vaccines in Cancer Immunotherapy. J. Immunol.Res. 2015. 794528. DOI: 10.1155/2015/794528

(33) Disis, M. L.; Coveler, A. L.; Higgins, D.; Fintak, P.; Waisman, J. R.; Reichow, J.; Slota, M.; Childs, J.; Dang, Y.; Salazar, L. G., A phase I trial of the safety and immunogenicity of a DNA-based vaccine encoding the HER2/neu (HER2) intracellular domain in subjects with HER2+breast cancer. J. Clin. Oncol. 2014, 32. DOI: 10.1200/jco.2014.32.15_suppl.616

(34) Braathen, R.; Spang, H. C. L.; Hinke, D. M.; Blazevski, J.; Bobic, S.; Fossum, E.; Bogen, B., A DNA Vaccine That Encodes an Antigen-Presenting Cell-Specific Heterodimeric Protein Protects against Cancer and Influenza. Mol. Ther. Methods Clin. Dev. 2020, 17, 378-392. DOI: 10.1016/j.omtm.2020.01.007

(35) Donnelly, J. J.; Wahren, B.; Liu, M. A., DNA vaccines: Progress and challenges. J. Immunol. 2005, 175, 633-639. DOI: 10.4049/jimmunol.175.2.633

(36) Holland, C. J.; Cole, D. K.; Godkin, A., Re-directing CD4(+) T cell responses with the flanking residues of MHC class II-bound peptides: the core is not enough. Front.Immunol. 2013, 4. 172. DOI: 10.3389/fimmu.2013.00172

(37) Neefjes, J.; Ovaa, H., A peptide's perspective on antigen presentation to the immune system. Nat. Chem. Biol. 2013, 9, 769-775. DOI: 10.1038/NCHEMBIO.1391 (38) Hu, Z.; Ott, P. A.; Wu, C. J., Towards personalized, tumour-specific, therapeutic vaccines for cancer. Nat. Rev. Immunol. 2018, 18, 168-182. DOI: 10.1038/nri.2017.131 (39) Branca, M. A., Rekindling cancer vaccines. Nat. Biotechnol. 2016, 34, 1019-1024. DOI: $10.1038 /$ nbt.3690

(40) Hilf, N.; Kuttruff-Coqui, S.; Frenzel, K.; Bukur, V.; Stevanovic, S.; Gouttefangeas, C.; Platten, M.; Tabatabai, G.; Dutoit, V.; van der Burg, S. H.; Straten, P. T.; MartinezRicarte, F.; Ponsati, B.; Okada, H.; Lassen, U.; Admon, A.; Ottensmeier, C. H.; Ulges, A.; Kreiter, S.; von Deimling, A.; Skardelly, M.; Migliorini, D.; Kroep, J. R.; Idorn, M.; Rodon, J.; Piro, J.; Poulsen, H. S.; Shraibman, B.; McCann, K.; Mendrzyk, R.; Loewer, M.; Stieglbauer, M.; Britten, C. M.; Capper, D.; Welters, M. J. P.; Sahuquillo, J.; Kiesel, K.; Derhovanessian, E.; Rusch, E.; Bunse, L.; Song, C.; Heesch, S.; Wagner, C.; Kemmer-Bruck, A.; Ludwig, J.; Castle, J. C.; Schoor, O.; Tadmor, A. D.; Green, E.; Fritsche, J.; Meyer, M.; Pawlowski, N.; Dorner, S.; Hoffgaard, F.; Roessler, B.; Maurer, D.; Weinschenk, T.; Reinhardt, C.; Huber, C.; Rammensee, H.-G.; Singh-Jasuja, H.; Sahin, U.; Dietrich, P.-Y.; Wick, W., Actively personalized vaccination trial for newly diagnosed glioblastoma. Nature 2019, 565, 240-245. DOI: 10.1038/s41586-018-0810y

(41) Keskin, D. B.; Anandappa, A. J.; Sun, J.; Tirosh, I.; Mathewson, N. D.; Li, S.; Oliveira, G.; Giobbie-Hurder, A.; Felt, K.; Gjini, E.; Shukla, S. A.; Hu, Z.; Li, L.; Le, P. M.; Allesoe, R. L.; Richman, A. R.; Kowalczyk, M. S.; Abdelrahman, S.; Geduldig, 
J. E.; Charbonneau, S.; Pelton, K.; Iorgulescu, J. B.; Elagina, L.; Zhang, W.; Olive, O.; McCluskey, C.; Olsen, L. R.; Stevens, J.; Lane, W. J.; Salazar, A. M.; Daley, H.; Wen, P. Y.; Chiocca, E. A.; Harden, M.; Lennon, N. J.; Gabriel, S.; Getz, G.; Lander, E. S.; Regev, A.; Ritz, J.; Neuberg, D.; Rodig, S. J.; Ligon, K. L.; Suva, M. L.; Wucherpfennig, K. W.; Hacohen, N.; Fritsch, E. F.; Livak, K. J.; Ott, P. A.; Wu, C. J.; Reardon, D. A., Neoantigen vaccine generates intratumoral $\mathrm{T}$ cell responses in phase Ib glioblastoma trial. Nature 2019, 565, 234-239. DOI: 10.1038/s41586-018-0792-9

(42) Kinkead, H. L.; Hopkins, A.; Lutz, E.; Wu, A. A.; Yarchoan, M.; Cruz, K.; Woolman, S.; Vithayathil, T.; Glickman, L. H.; Ndubaku, C. O.; McWhirter, S. M.; Dubensky, T. W., Jr.; Armstrong, T. D.; Jaffee, E. M.; Zaidi, N., Combining STINGbased neoantigen-targeted vaccine with checkpoint modulators enhances antitumor immunity in murine pancreatic cancer. Jci Insight 2018, 3. e122857. DOI: 10.1172/jci.insight.122857

(43) Shi, G.-N.; Zhang, C.-N.; Xu, R.; Niu, J.-F.; Song, H.-J.; Zhang, X.-Y.; Wang, W. W.; Wang, Y.-M.; Li, C.; Wei, X.-Q.; Kong, D.-L., Enhanced antitumor immunity by targeting dendritic cells with tumor cell lysate-loaded chitosan nanoparticles vaccine. Biomaterials 2017, 113, 191-202. DOI: 10.1016/j.biomaterials.2016.10.047

(44) Han, X.; Shen, S.; Fan, Q.; Chen, G.; Archibong, E.; Dotti, G.; Liu, Z.; Gu, Z.; Wang, C., Red blood cell-derived nanoerythrosome for antigen delivery with enhanced cancer immunotherapy. Sci. Adv. 2019, 5. eaaw6870. DOI: 10.1126/sciadv.aaw6870

(45) Yang, R.; Xu, J.; Xu, L.; Sun, X.; Chen, Q.; Zhao, Y.; Peng, R.; Liu, Z., Cancer Cell Membrane-Coated Adjuvant Nanoparticles with Mannose Modification for Effective Anticancer Vaccination. Acs Nano 2018, 12, 5121-5129. DOI: 10.1021/acsnano.7b09041

(46) Morishita, M.; Takahashi, Y.; Matsumoto, A.; Nishikawa, M.; Takakura, Y., Exosome-based tumor antigens-adjuvant co-delivery utilizing genetically engineered tumor cell-derived exosomes with immunostimulatory CpG DNA. Biomaterials 2016, 111, 55-65. DOI: 10.1016/j.biomaterials.2016.09.031

(47) Taghikhani, A.; Farzaneh, F.; Sharifzad, F.; Mardpour, S.; Ebrahimi, M.; Hassan, Z. M., Engineered Tumor-Derived Extracellular Vesicles: Potentials in Cancer Immunotherapy. Front.Immunol. 2020, 11. 221. DOI: 10.3389/fimmu.2020.00221

(48) Tanyi, J. L.; Bobisse, S.; Ophir, E.; Tuyaerts, S.; Roberti, A.; Genolet, R.; Baumgartner, P.; Stevenson, B. J.; Iseli, C.; Dangaj, D.; Czerniecki, B.; Semilietof, A.; Racle, J.; Michel, A.; Xenarios, I.; Chiang, C.; Monos, D. S.; Torigian, D. A.; Nisenbaum, H. L.; Michielin, O.; June, C. H.; Levine, B. L.; Powel, D. J., Jr.; Gfeller, D.; Mick, R.; Dafni, U.; Zoete, V.; Harari, A.; Coukos, G.; Kandalaft, L. E., Personalized cancer vaccine effectively mobilizes antitumor $\mathrm{T}$ cell immunity in ovarian cancer. Sci Transl Med 2018, 10. eaao5931. DOI: 10.1126/scitranslmed.aao5931

(49) Kuai, R.; Yuan, W.; Son, S.; Nam, J.; Xu, Y.; Fan, Y.; Schwendeman, A.; Moon, J. J., Elimination of established tumors with nanodisc-based combination chemoimmunotherapy. Sci. Adv. 2018, 4. eaao1736. DOI: $10.1126 /$ sciadv.aao1736

(50) Goto, T., Radiation as an In Situ Auto-Vaccination: Current Perspectives and Challenges. Vaccines 2019, 7. 100. DOI: 10.3390/vaccines7030100 
(51) Chen, Q.; Xu, L.; Liang, C.; Wang, C.; Peng, R.; Liu, Z., Photothermal therapy with immune-adjuvant nanoparticles together with checkpoint blockade for effective cancer immunotherapy. Nat. Commun. 2016, 7. 13193. DOI: 10.1038/ncomms13193

(52) Xu, C.; Yu, Y.; Sun, Y.; Kong, L.; Yang, C.; Hu, M.; Yang, T.; Zhang, J.; Hu, Q.; Zhang, Z., Transformable Nanoparticle-Enabled Synergistic Elicitation and Promotion of Immunogenic Cell Death for Triple-Negative Breast Cancer Immunotherapy. Adv. Funct.Mater. 2019, 29. 1905213. DOI: 10.1002/adfm.201905213

(53) Wang, T.; Wang, D.; Yu, H.; Feng, B.; Zhou, F.; Zhang, H.; Zhou, L.; Jiao, S.; Li, Y., A cancer vaccine-mediated postoperative immunotherapy for recurrent and metastatic tumors. Nat. Commun. 2018, 9. 1532. DOI: 10.1038/s41467-018-03915-4

(54) Yu, X.; Dai, Y.; Zhao, Y.; Qi, S.; Liu, L.; Lu, L.; Luo, Q.; Zhang, Z., Melittin-lipid nanoparticles target to lymph nodes and elicit a systemic anti-tumor immune response. Nat. Commun. 2020, 11. 1110. DOI: 10.1038/s41467-020-14906-9

(55) Asadzadeh, Z.; Safarzadeh, E.; Safaei, S.; Baradaran, A.; Mohammadi, A.; Hajiasgharzadeh, K.; Derakhshani, A.; Argentiero, A.; Silvestris, N.; Baradaran, B., Current Approaches for Combination Therapy of Cancer: The Role of Immunogenic Cell Death. Cancers 2020, 12. 1047. DOI: 10.3390/cancers12041047

(56) Kroemer, G.; Galluzzi, L.; Kepp, O.; Zitvogel, L., Immunogenic Cell Death in Cancer Therapy. In Annual Review of Immunology, Vol 31, Littman, D. R.; Yokoyama, W. M., Eds. Annu. Rev. Immunol. 2013, 31, 51-72. DOI: 10.1146/annurev-immunol032712-100008

(57) Green, D. R.; Ferguson, T.; Zitvogel, L.; Kroemer, G., Immunogenic and tolerogenic cell death. Nat. Rev. Immunol. 2009, 9, 353-363. DOI: 10.1038/nri2545

(58) Di Pasquale, A.; Preiss, S.; Tavares Da Silva, F.; Garcon, N., Vaccine Adjuvants: from 1920 to 2015 and Beyond. Vaccines 2015, 3, 320-343. DOI:10.3390/vaccines3020320

(59) Gan, J.; Du, G.; He, C.; Jiang, M.; Mou, X.; Xue, J.; Sun, X., Tumor cell membrane enveloped aluminum phosphate nanoparticles for enhanced cancer vaccination. $J$ Control Release 2020, 326, 297-309. DOI:10.1016/j.jconrel.2020.07.008

(60)Yang, F.; Shi, K.; Jia, Y. P.; Hao, Y.; Peng, J. R.; Yuan, L. P.; Chen, Y.; Pan, M.; Qian, Z. Y., A biodegradable thermosensitive hydrogel vaccine for cancer immunotherapy. Appl. Mater. Today 2020, 19, 100608. DOI: 10.1016/j.apmt.2020.100608

(61) Dubensky, T. W., Jr.; Reed, S. G., Adjuvants for cancer vaccines. Semin.Immunol. 2010, 22, 155-161. DOI: 10.1016/j.smim.2010.04.007

(62) Kim, C. G.; Kye, Y.-C.; Yun, C.-H., The Role of Nanovaccine in CrossPresentation of Antigen-Presenting Cells for the Activation of CD8(+) T Cell Responses. Pharmaceutics 2019, 11. 612. DOI: 10.3390/pharmaceutics11110612

(63) Beesu, M.; Caruso, G.; Salyer, A. C. D.; Khetani, K. K.; Sil, D.; Weerasinghe, M.; Tanji, H.; Ohto, U.; Shimizu, T.; David, S. A., Structure-Based Design of Human TLR8-Specific Agonists with Augmented Potency and Adjuvanticity. J. Med. Chem. 2015, 58, 7833-7849. DOI: 10.1021/acs.jmedchem.5b01087 
(64) Li, M.; Zhou, H.; Yang, C.; Wu, Y.; Zhou, X.; Liu, H.; Wang, Y., Bacterial outer membrane vesicles as a platform for biomedical applications: An update. $J$ Control Release 2020, 323, 253-268. DOI: 10.1016/j.jconrel.2020.04.031

(65) Kato, K.; Omura, H.; Ishitani, R.; Nureki, O., Cyclic GMP-AMP as an Endogenous Second Messenger in Innate Immune Signaling by Cytosolic DNA. Annu. Rev. Biochem., 2017; 86, 541-566. DOI: 10.1146/annurev-biochem-061516-044813

(66) Chin, E. N.; Yu, C.; Vartabedian, V. F.; Jia, Y.; Kumar, M.; Gamo, A. M.; Vernier, W.; Ali, S. H.; Kissai, M.; Lazar, D. C.; Nguyen, N.; Pereira, L. E.; Benish, B.; Woods, A. K.; Joseph, S. B.; Chu, A.; Johnson, K. A.; Sander, P. N.; Martinez-Pena, F.; Hampton, E. N.; Young, T. S.; Wolan, D. W.; Chatterjee, A. K.; Schultz, P. G.; Petrassi, H. M.; Teijaro, J. R.; Lairson, L. L., Antitumor activity of a systemic STING-activating non-nucleotide cGAMP mimetic. Science 2020, 369, 993-999. DOI:10.1126/science.abb4255

(67) Miao, L.; Li, L.; Huang, Y.; Delcassian, D.; Chahal, J.; Han, J.; Shi, Y.; Sadtler, K.; Gao, W.; Lin, J.; Doloff, J. C.; Langer, R.; Anderson, D. G., Delivery of mRNA vaccines with heterocyclic lipids increases anti-tumor efficacy by STING-mediated immune cell activation. Nat. Biotechnol. 2019, 37, 1174-1185. DOI: 10.1038/s41587019-0247-3

(68) Yim, H.; Park, W.; Kim, D.; Fahmy, T. M.; Na, K., A self-assembled polymeric micellar immunomodulator for cancer treatment based on cationic amphiphilic polymers. Biomaterials 2014, 35, 9912-9919.DOI: 10.1016/j.biomaterials.2014.08.029 (69) Wang, X.; Li, X.; Yoshiyuki, K.; Watanabe, Y.; Sogo, Y.; Ohno, T.; Tsuji, N. M.; Ito, A., Comprehensive Mechanism Analysis of Mesoporous-Silica-NanoparticleInduced Cancer Immunotherapy. Adv. Healthc. Mater. 2016, 5, 1169-1176. DOI: 10.1002/adhm.201501013

(70) Li, A. W.; Sobral, M. C.; Badrinath, S.; Choi, Y.; Graveline, A.; Stafford, A. G.; Weaver, J. C.; Dellacherie, M. O.; Shih, T.-Y.; Ali, O. A.; Kim, J.; Wucherpfennig, K. W.; Mooney, D. J., A facile approach to enhance antigen response for personalized cancer vaccination. Nat. Mater. 2018, 17, 528-534. DOI: 10.1038/s41563-018-0028-2 (71) Li, X.; Wang, X.; Ito, A., Tailoring inorganic nanoadjuvants towards nextgeneration vaccines. Chem. Soc. Rev. 2018, 47, 4954-4980. DOI: 10.1039/c8cs00028j (72) Tsoras, A. N.; Champion, J. A., Protein and Peptide Biomaterials for Engineered Subunit Vaccines and Immunotherapeutic Applications. In Annual Review of Chemical and Biomolecular Engineering, Vol 10, Prausnitz, J. M., Ed. 2019; Vol. 10, pp 337-359. DOI: 10.1146/annurev-chembioeng-060718-030347

(73) McDonald, D. M.; Byrne, S. N.; Payne, R. J., Synthetic self-adjuvanting glycopeptide cancer vaccines. Front.Chem. 2015, 3. 60. DOI: 10.3389/fchem.2015.00060

(74) Zhao, G.; Chandrudu, S.; Skwarczynski, M.; Toth, I., The application of selfassembled nanostructures in peptide-based subunit vaccine development. Eur. Polym.J. 2017, 93, 670-681. DOI: 10.1016/j.eurpolymj.2017.02.014

(75) Chesson, C. B.; Huelsmann, E. J.; Lacek, A. T.; Kohlhapp, F. J.; Webb, M. F.; Nabatiyan, A.; Zloza, A.; Rudra, J. S., Antigenic peptide nanofibers elicit adjuvant-free 
CD8(+) $\mathrm{T}$ cell responses. Vaccine 2014, 32, 1174-1180. DOI: 10.1016/j.vaccine.2013.11.047

(76) Rudra, J. S.; Tian, Y. F.; Jung, J. P.; Collier, J. H., A self-assembling peptide acting as an immune adjuvant. Proc. Natl. Acad. Sci. U.S.A. 2010, 107, 622-627. DOI: 10.1073/pnas.0912124107

(77) Rudra, J. S.; Sun, T.; Bird, K. C.; Daniels, M. D.; Gasiorowski, J. Z.; Chong, A. S.; Collier, J. H., Modulating Adaptive Immune Responses to Peptide Self-Assemblies. Acs Nano 2012, 6, 1557-1564. DOI: 10.1021/nn204530r

(78) Wen, Y.; Waltman, A.; Han, H.; Collier, J. H., Switching the Immunogenicity of Peptide Assemblies Using Surface Properties. Acs Nano 2016, 10, 9274-9286. DOI: 10.1021/acsnano.6b03409

(79) Tian, Y.; Wang, H.; Liu, Y.; Mao, L.; Chen, W.; Zhu, Z.; Liu, W.; Zheng, W.; Zhao, Y.; Kong, D.; Yang, Z.; Zhang, W.; Shao, Y.; Jiang, X., A Peptide-Based Nanofibrous Hydrogel as a Promising DNA Nanovector for Optimizing the Efficacy of HIV Vaccine. Nano Lett. 2014, 14, 1439-1445. DOI: 10.1021/nl404560v

(80) Demircan, M. B.; Tohumeken, S.; Gunduz, N.; Khalily, M. A.; Tekinay, T.; Guler, M. O.; Tekinay, A. B., Biotin Functionalized Self-Assembled Peptide Nanofiber as an Adjuvant for Immunomodulatory Response. Biotechnol. J. 2020, 2000100. DOI: 10.1002/biot.202000100

(81) Wang, H.; Luo, Z.; Wang, Y.; He, T.; Yang, C.; Ren, C.; Ma, L.; Gong, C.; Li, X.; Yang, Z., Enzyme-Catalyzed Formation of Supramolecular Hydrogels as Promising Vaccine Adjuvants. Adv. Funct.Mater. 2016, 26, 1822-1829. DOI: 10.1002/adfm.201505188

(82) Yang, C.; Shi, F.; Li, C.; Wang, Y.; Wang, L.; Yang, Z., Single Dose of Protein Vaccine with Peptide Nanofibers As Adjuvants Elicits Long-Lasting Antibody Titer. ACS Biomater.Sci. Eng. 2018, 4, 2000-2006. DOI: 10.1021/acsbiomaterials.7b00488

(83) Liu, Y.; Wang, Y.; Yu, F.; Zhang, Z.; Yang, Z.; Zhang, W.; Wang, P. G.; Zhao, W., Potentiating the immune response of MUC1-based antitumor vaccines using a peptide-based nanovector as a promising vaccine adjuvant. ChemComm 2017, 53, 9486-9489. DOI: 10.1039/c7cc04386d

(84) Luo, Z.; Wu, Q.; Yang, C.; Wang, H.; He, T.; Wang, Y.; Wang, Z.; Chen, H.; Li, X.; Gong, C.; Yang, Z., A Powerful CD8(+) T-Cell Stimulating D-Tetra-Peptide Hydrogel as a Very Promising Vaccine Adjuvant. Adv. Mater. 2017, 29. UNSP 1601776. DOI: 10.1002/adma.201601776

(85) Yuba, E.; Harada, A.; Sakanishi, Y.; Watarai, S.; Kono, K., A liposome-based antigen delivery system using $\mathrm{pH}$-sensitive fusogenic polymers for cancer immunotherapy. Biomaterials 2013, 34, 3042-3052. DOI: 10.1016/j.biomaterials.2012.12.031

(86) Niikura, K.; Matsunaga, T.; Suzuki, T.; Kobayashi, S.; Yamaguchi, H.; Orba, Y.; Kawaguchi, A.; Hasegawa, H.; Kajino, K.; Ninomiya, T.; Ijiro, K.; Sawa, H., Gold Nanoparticles as a Vaccine Platform: Influence of Size and Shape on Immunological Responses in Vitro and in Vivo. Acs Nano 2013, 7, 3926-3938. DOI: 10.1021/nn3057005 
(87) Kumar, S.; Anselmo, A. C.; Banerjee, A.; Zakrewsky, M.; Mitragotri, S., Shape and size-dependent immune response to antigen-carrying nanoparticles. $J$ Control Release 2015, 220, 141-148. DOI: 10.1016/j.jconrel.2015.09.069

(88) Cheng, L.; Wang, Y.; Huang, L., Exosomes from M1-Polarized Macrophages Potentiate the Cancer Vaccine by Creating a Pro-inflammatory Microenvironment in the Lymph Node. Mol. Ther. 2017, 25, 1665-1675. DOI: 10.1016/j.ymthe.2017.02.007 (89) Sahdev, P.; Ochyl, L. J.; Moon, J. J., Biomaterials for Nanoparticle Vaccine Delivery Systems. Pharm. Res. 2014, 31, 2563-2582. DOI: 10.1007/s11095-014-1419$\mathrm{y}$

(90) Silva, J. M.; Videira, M.; Gaspar, R.; Preat, V.; Florindo, H. F., Immune system targeting by biodegradable nanoparticles for cancer vaccines. J Control Release 2013, 168, 179-199. DOI: 10.1016/j.jconrel.2013.03.010

(91) Fan, Y. N.; Li, M.; Luo, Y. L.; Chen, Q.; Wang, L.; Zhang, H. B.; Shen, S.; Gu, Z.; Wang, J., Cationic lipid-assisted nanoparticles for delivery of mRNA cancer vaccine. Biomater. Sci. 2018, 6, 3009-3018. DOI: 10.1039/c8bm00908b

(92) Kim, H.; Griffith, T. S.; Panyam, J., Poly(D,L-lactide-co-glycolide) Nanoparticles as Delivery Platforms for TLR7/8 Agonist-Based Cancer Vaccine. J. Pharmacol. Exp. Ther. 2019, 370, 715-724. DOI: 10.1124/jpet.118.254953

(93) Song, W. T.; Musetti, S. N.; Huang, L., Nanomaterials for cancer immunotherapy. Biomaterials 2017, 148, 16-30. DOI: 10.1016/j.biomaterials.2017.09.017

(94) Shanmugaraj, B.; Priya, L. B.; Mahalakshmi, B.; Subbiah, S.; Hu, R.-M.; Velmurugan, B. K.; Baskaran, R., Bacterial and viral vectors as vaccine delivery vehicles for breast cancer therapy. Life Sci 2020, 250, 117550. DOI: 10.1016/j.lfs.2020.117550

(95) Garg, S.; Oran, A. E.; Hon, H.; Jacob, J., The hybrid cytomegalovirus enhancer/chicken beta-actin promoter along with woodchuck hepatitis virus posttranscriptional regulatory element enhances the protective efficacy of DNA vaccines. J. Immunol. 2004, 173, 550-558. DOI: 10.4049/jimmunol.173.1.550

(96) Flickinger, J. C., Jr.; Singh, J.; Carlson, R.; Leong, E.; Baybutt, T. R.; Barton, J.; Caparosa, E.; Pattison, A.; Rappaport, J. A.; Roh, J.; Zhan, T.; Bashir, B.; Waldman, S. A.; Snook, A. E., Chimeric Ad5.F35 vector evades anti-adenovirus serotype 5 neutralization opposing GUCY2C-targeted antitumor immunity. J. Immunother.Cancer 2020, 8, e001046. DOI:10.1136/jitc-2020-001046

(97) Liu, S.; Jiang, Q.; Zhao, X.; Zhao, R.; Wang, Y.; Wang, Y.; Liu, J.; Shang, Y.; Zhao, S.; Wu, T.; Zhang, Y.; Nie, G.; Ding, B., A DNA nanodevice-based vaccine for cancer immunotherapy. Nat. Mater. 2020. DOI:10.1038/s41563-020-0793-6

(98) Chen, D. S.; Mellman, I., Oncology Meets Immunology: The Cancer-Immunity Cycle. Immunity 2013, 39, 1-10. DOI:10.1016/j.immuni.2013.07.012

(99) Hailemichael, Y.; Dai, Z.; Jaffarzad, N.; Ye, Y.; Medina, M. A.; Huang, X.-F.; Dorta-Estremera, S. M.; Greeley, N. R.; Nitti, G.; Peng, W.; Liu, C.; Lou, Y.; Wang, Z.; Ma, W.; Rabinovich, B.; Schluns, K. S.; Davis, R. E.; Hwu, P.; Overwijk, W. W., Persistent antigen at vaccination sites induces tumor-specific CD8(+) $\mathrm{T}$ cell sequestration, dysfunction and deletion. Nat. Med. 2013, 19, 465-472. DOI: 10.1038/nm.3105 
(100) Reddy, S. T.; Swartz, M. A.; Hubbell, J. A., Targeting dendritic cells with biomaterials: developing the next generation of vaccines. Trends Immunol. 2006, 27, 573-579. DOI: 10.1016/j.it.2006.10.005

(101) Zhang, Y.-N.; Lazarovits, J.; Poon, W.; Ouyang, B.; Nguyen, L. N. M.; Kingston, B. R.; Chan, W. C. W., Nanoparticle Size Influences Antigen Retention and Presentation in Lymph Node Follicles for Humoral Immunity. Nano Lett. 2019, 19, 7226-7235. DOI: 10.1021/acs.nanolett.9b02834

(102) Gretz, J. E.; Norbury, C. C.; Anderson, A. O.; Proudfoot, A. E. I.; Shaw, S., Lymph-borne chemokines and other low molecular weight molecules reach high endothelial venules via specialized conduits while a functional barrier limits access to the lymphocyte microenvironments in lymph node cortex. J. Exp. Med. 2000, 192, 1425-1439. DOI: 10.1084/jem.192.10.1425

(103) Kim, H.; Uto, T.; Akagi, T.; Baba, M.; Akashi, M., Amphiphilic Poly(Amino Acid) Nanoparticles Induce Size-Dependent Dendritic Cell Maturation. Adv. Funct.Mater. 2010, 20, 3925-3931. DOI: 10.1002/adfm.201000021

(104) Mehta, N. K.; Moynihan, K. D.; Irvine, D. J., Engineering New Approaches to Cancer Vaccines. Cancer Immunol.Res. 2015, 3, 836-843. DOI: 10.1158/23266066.CIR-15-0112

(105) Niu, L.; Chu, L. Y.; Burton, S. A.; Hansen, K. J.; Panyam, J., Intradermal delivery of vaccine nanoparticles using hollow microneedle array generates enhanced and balanced immune response. $J$ Control Release 2019, 294, 268-278. DOI: 10.1016/j.jconrel.2018.12.026

(106) Huu Thuy Trang, D.; Yin, Y.; Thambi, T.; Thanh Loc, N.; Phan, V. H. G.; Lee, M. S.; Lee, J. E.; Kim, J.; Jeong, J. H.; Lee, D. S., Smart vaccine delivery based on microneedle arrays decorated with ultra-pH-responsive copolymers for cancer immunotherapy. Biomaterials 2018, 185, 13-24. DOI: 10.1016/j.biomaterials.2018.09.008

(107) Thanh Loc, N.; Cha, B. G.; Choi, Y.; Im, J.; Kim, J., Injectable dual-scale mesoporous silica cancer vaccine enabling efficient delivery of antigen/adjuvantloaded nanoparticles to dendritic cells recruited in local macroporous scaffold. Biomaterials 2020, 239. 119859. DOI: 10.1016/j.biomaterials.2020.119859

(108) Weber, J. S.; Vogelzang, N. J.; Ernstoff, M. S.; Goodman, O. B.; Cranmer, L. D.; Marshall, J. L.; Miles, S.; Rosario, D.; Diamond, D. C.; Qiu, Z.; Obrocea, M.; Bot, A., A Phase 1 Study of a Vaccine Targeting Preferentially Expressed Antigen in Melanoma and Prostate-specific Membrane Antigen in Patients With Advanced Solid Tumors. J. Immunother. 2011, 34, 556-567. DOI: 10.1097/CJI.0b013e3182280db1

(109) Johansen, P.; Kuendig, T. M., Intralymphatic Immunotherapy and Vaccination in Mice. Jove-j Vis Exp 2014, 84, e51031. DOI: 10.3791/51031

(110) Wu, T. Y. H.; Singh, M.; Miller, A. T.; De Gregorio, E.; Doro, F.; D'Oro, U.; Skibinski, D. A. G.; Mbow, M. L.; Bufali, S.; Herman, A. E.; Cortez, A.; Li, Y.; Nayak, B. P.; Tritto, E.; Filippi, C. M.; Otten, G. R.; Brito, L. A.; Monaci, E.; Li, C.; Aprea, S.; Valentini, S.; Calabro, S.; Laera, D.; Brunelli, B.; Caproni, E.; Malyala, P.; Panchal, R. G.; Warren, T. K.; Bavari, S.; O'Hagan, D. T.; Cooke, M. P.; Valiante, N. M., Rational 
design of small molecules as vaccine adjuvants. Sci Transl Med 2014, 6, 263ra160. DOI: 10.1126/scitranslmed.3009980

(111) Jewell, C. M.; Lopez, S. C. B.; Irvine, D. J., In situ engineering of the lymph node microenvironment via intranodal injection of adjuvant-releasing polymer particles. Proc. Natl. Acad. Sci. U.S.A. 2011, 108, 15745-15750. DOI: 10.1073/pnas.1105200108 (112) Geskin, L. J.; Damiano, J. J.; Patrone, C. C.; Butterfield, L. H.; Kirkwood, J. M.; Falo, L. D., Three antigen-loading methods in dendritic cell vaccines for metastatic melanoma. Melanoma Res. 2018, 28, 211-221. DOI: 10.1097/CMR.0000000000000441

(113) Yao, L.; Xue, X.; Yu, P.; Ni, Y.; Chen, F., Evans Blue Dye: A Revisit of Its Applications in Biomedicine. Contrast Media Mol I 2018, UNSP 7628037. DOI: 10.1155/2018/7628037

(114) Bachmann, M. F.; Jennings, G. T., Vaccine delivery: a matter of size, geometry, kinetics and molecular patterns. Nat. Rev. Immunol. 2010, 10, 787-796. DOI: 10.1038/nri2868

(115) Reddy, S. T.; van der Vlies, A. J.; Simeoni, E.; Angeli, V.; Randolph, G. J.; O'Neill, C. P.; Lee, L. K.; Swartz, M. A.; Hubbell, J. A., Exploiting lymphatic transport and complement activation in nanoparticle vaccines. Nat. Biotechnol. 2007, 25, 11591164. DOI: $10.1038 / n b t 1332$

(116) Zhang, Y.; Pan, J.; Li, H.; Yu, D.; Wu, T.; Wang, L.; Wang, Y.; Zhou, L.; Zheng, S., Albumin Based Nanomedicine for Enhancing Tacrolimus Safety and Lymphatic Targeting Efficiency. J Biomed Nanotechnol 2019, 15, 1313-1324. DOI: 10.1166/jbn.2019.2777

(117) Liu, H.; Moynihan, K. D.; Zheng, Y.; Szeto, G. L.; Li, A. V.; Huang, B.; Van Egeren, D. S.; Park, C.; Irvine, D. J., Structure-based programming of lymph-node targeting in molecular vaccines. Nature 2014, 507, 519-522. DOI: 10.1038/nature12978

(118) Moynihan, K. D.; Holden, R. L.; Mehta, N. K.; Wang, C.; Karver, M. R.; Dinter, J.; Liang, S.; Abraham, W.; Melo, M. B.; Zhang, A. Q.; Li, N.; Le Gall, S.; Pentelute, B. L.; Irvine, D. J., Enhancement of Peptide Vaccine Immunogenicity by Increasing Lymphatic Drainage and Boosting Serum Stability. Cancer Immunol.Res. 2018, 6, 1025-1038. DOI: 10.1158/2326-6066.CIR-17-0607

(119) De Vrieze, J.; Louage, B.; Deswarte, K.; Zhong, Z.; De Coen, R.; Van Herck, S.; Nuhn, L.; Frich, C. K.; Zelikin, A. N.; Lienenklaus, S.; Sanders, N. N.; Lambrecht, B. N.; David, S. A.; De Geest, B. G., Potent Lymphatic Translocation and Spatial Control Over Innate Immune Activation by Polymer-Lipid Amphiphile Conjugates of SmallMolecule TLR7/8 Agonists. Angew.Chem. Int. Ed. 2019, 58, 15390-15395. DOI: 10.1002/anie.201905687

(120) Zhu, G.; Lynn, G. M.; Jacobson, O.; Chen, K.; Liu, Y.; Zhang, H.; Ma, Y.; Zhang, F.; Tian, R.; Ni, Q.; Cheng, S.; Wang, Z.; Lu, N.; Yung, B. C.; Wang, Z.; Lang, L.; Fu, X.; Jin, A.; Weiss, I. D.; Vishwasrao, H.; Niu, G.; Shroff, H.; Klinman, D. M.; Seder, R. A.; Chen, X., Albumin/vaccine nanocomplexes that assemble in vivo for combination cancer immunotherapy. Nat. Commun. 2017, 8. 1954. DOI: 10.1038/s41467-017-02191-y 
(121) Yoo, E.; Salyer, A. C. D.; Brush, M. J. H.; Li, Y.; Trautman, K. L.; Shukla, N. M.; De Beuckelaer, A.; Lienenklaus, S.; Deswarte, K.; Lambrecht, B. N.; De Geest, B. G.; David, S. A., Hyaluronic Acid Conjugates of TLR7/8 Agonists for Targeted Delivery to Secondary Lymphoid Tissue. Bioconjug.Chem. 2018, 29, 2741-2754. DOI: 10.1021/acs.bioconjchem.8b00386

(122) Irvine, D. J.; Aung, A.; Silva, M., Controlling timing and location in vaccines. Adv. Drug Deliv.Rev. 2020, In Press. DOI:10.1016/j.addr.2020.06.019

(123) Fehres, C. M.; Unger, W. W. J.; Garcia-Vallejo, J. J.; van Kooyk, Y., Understanding the biology of antigen cross-presentation for the design of vaccines against cancer. Front.Immunol. 2014, 5, UNSP 149. DOI: 10.3389/fimmu.2014.00149 (124) Oberli, M. A.; Reichmuth, A. M.; Dorkin, J. R.; Mitchell, M. J.; Fenton, O. S.; Jaklenec, A.; Anderson, D. G.; Langer, R.; Blankschtein, D., Lipid Nanoparticle Assisted mRNA Delivery for Potent Cancer Immunotherapy. Nano Lett. 2017, 17, 1326-1335. DOI: 10.1021/acs.nanolett.6b03329

(125) Kranz, L. M.; Diken, M.; Haas, H.; Kreiter, S.; Loquai, C.; Reuter, K. C.; Meng, M.; Fritz, D.; Vascotto, F.; Hefesha, H.; Grunwitz, C.; Vormehr, M.; Huesemann, Y.; Selmi, A.; Kuhn, A. N.; Buck, J.; Derhovanessian, E.; Rae, R.; Attig, S.; Diekmann, J.; Jabulowsky, R. A.; Heesch, S.; Hassel, J.; Langguth, P.; Grabbe, S.; Huber, C.; Tuereci, O.; Sahin, U., Systemic RNA delivery to dendritic cells exploits antiviral defence for cancer immunotherapy. Nature 2016, 534, 396-401. DOI: 10.1038/nature18300

(126) Liu, Q.; Chen, X. M.; Jia, J. L.; Zhang, W. F.; Yang, T. Y.; Wang, L. Y.; Ma, G. H., pH-Responsive Poly(D,L-lactic-co-glycolic acid) Nanoparticles with Rapid Antigen Release Behavior Promote Immune Response. Acs Nano 2015, 9, 4925-4938. DOI: $10.1021 / \mathrm{nn} 5066793$

(127) Wang, K.; Wen, S.; He, L.; Li, A.; Li, Y.; Dong, H.; Li, W.; Ren, T.; Shi, D.; Li, Y., "Minimalist" Nanovaccine Constituted from Near Whole Antigen for Cancer Immunotherapy. Acs Nano 2018, 12, 6398-6409. DOI: 10.1021/acsnano.8b00558

(128) Hjalmsdottir, A.; Buehler, C.; Vonwil, V.; Roveri, M.; Hakerud, M.; WaeckerleMen, Y.; Gander, B.; Johansen, P., Cytosolic Delivery of Liposomal Vaccines by Means of the Concomitant Photosensitization of Phagosomes. Molecular Pharmaceutics 2016, 13, 320-329. DOI: 10.1021/acs.molpharmaceut.5b00394

(129) Chen, J.; Li, Z.; Huang, H.; Yang, Y.; Ding, Q.; Mai, J.; Guo, W.; Xu, Y., Improved antigen cross-presentation by polyethyleneimine-based nanoparticles. Int. $J$. Nanomedicine 2011, 6, 77-84. DOI: 10.2147/IJN.S15457

(130) Jiang, D.; Mu, W.; Pang, X.; Liu, Y.; Zhang, N.; Song, Y.; Garg, S., Cascade Cytosol Delivery of Dual-Sensitive Micelle-Tailored Vaccine for Enhancing Cancer Immunotherapy. ACS Appl. Mater.Interfaces 2018, 10, 37797-37811. DOI: 10.1021/acsami.8b09946

(131) Wang, Y.; Lin, Y.-X.; Wang, J.; Qiao, S.-L.; Liu, Y.-Y.; Dong, W.-Q.; Wang, J.; An, H.-W.; Yang, C.; Mamuti, M.; Wang, L.; Huang, B.; Wang, H., In Situ Manipulation of Dendritic Cells by an Autophagy-Regulative Nanoactivator Enables Effective Cancer Immunotherapy. Acs Nano 2019, 13, 7568-7577. DOI: 10.1021/acsnano.9b00143 
(132) Anderson, A. C.; Joller, N.; Kuchroo, V. K., Lag-3, Tim-3, and TIGIT: Coinhibitory Receptors with Specialized Functions in Immune Regulation. Immunity 2016, 44, 989-1004. DOI: 10.1016/j.immuni.2016.05.001

(133) Gatti-Mays, M. E.; Redman, J. M.; Collins, J. M.; Bilusic, M., Cancer vaccines: Enhanced immunogenic modulation through therapeutic combinations. Hum Vaccin Immunother 2017, 13, 2561-2574. DOI: 10.1080/21645515.2017.1364322

(134) Zhou, Z.; Pang, J.; Wu, X.; Wu, W.; Chen, X.; Kong, M., Reverse immune suppressive microenvironment in tumor draining lymph nodes to enhance anti-PD1 immunotherapy via nanovaccine complexed microneedle. Nano Res. 2020, 13, 15091518. DOI: $10.1007 / \mathrm{s} 12274-020-2737-5$

(135) Golay, J.; Andrea, A. E., Combined Anti-Cancer Strategies Based on AntiCheckpoint Inhibitor Antibodies. Antibodies 2020, 9, 17. DOI:10.3390/antib9020017 (136) Le, D. T.; Lutz, E.; Uram, J. N.; Sugar, E. A.; Onners, B.; Solt, S.; Zheng, L.; Diaz, L. A., Jr.; Donehower, R. C.; Jaffee, E. M.; Laheru, D. A., Evaluation of Ipilimumab in Combination With Allogeneic Pancreatic Tumor Cells Transfected With a GM-CSF Gene in Previously Treated Pancreatic Cancer. J Immunother 2013, 36, 382389. DOI: 10.1097/CJI.0b013e31829fb7a2

(137) Liu, L.; Wang, Y.; Miao, L.; Liu, Q.; Musetti, S.; Li, J.; Huang, L., Combination Immunotherapy of MUC1 mRNA Nano-vaccine and CTLA-4 Blockade Effectively Inhibits Growth of Triple Negative Breast Cancer. Mol. Ther. 2018, 26, 45-55. DOI: 10.1016/j.ymthe.2017.10.020

(138) Xue, S.; Hu, M.; Iyer, V.; Yu, J. M., Blocking the PD-1/PD-L1 pathway in glioma: a potential new treatment strategy. J. Hematol. Oncol. 2017, 10, 10, 81. DOI: 10.1186/s13045-017-0455-6

(139) Dyck, L.; Wilk, M. M.; Raverdeau, M.; Misiak, A.; Boon, L.; Mills, K. H. G., Anti-PD-1 inhibits Foxp3(+) Treg cell conversion and unleashes intratumoural effector $\mathrm{T}$ cells thereby enhancing the efficacy of a cancer vaccine in a mouse model. Cancer Immunol.Immunother. 2016, 65, 1491-1498. DOI: 10.1007/s00262-016-1906-6

(140) Zhao, H.; Xu, J.; Li, Y.; Guan, X.; Han, X.; Xu, Y.; Zhou, H.; Peng, R.; Wang, J.; Liu, Z., Nanoscale Coordination Polymer Based Nanovaccine for Tumor Immunotherapy. ACS Nano 2019, 13, 13127-13135. DOI: 10.1021/acsnano.9b05974 (141) He, Q.; Li, J.; Yin, W.; Song, Z.; Zhang, Z.; Yi, T.; Tang, J.; Wu, D.; Lu, Y.; Wang, Z.; Liu, D.; Zhang, X.; Hu, Z.; Gao, J., Low-dose paclitaxel enhances the antitumor efficacy of GM-CSF surface-modified whole-tumor-cell vaccine in mouse model of prostate cancer. Cancer Immunol.Immunother. 2011, 60, 715-730. DOI: 10.1007/s00262-011-0988-4

(142) Rettig, L.; Seidenberg, S.; Parvanova, I.; Samaras, P.; Knuth, A.; Pascolo, S., Gemcitabine depletes regulatory T-cells in human and mice and enhances triggering of vaccine-specific cytotoxic T-cells. Int. J. Cancer 2011, 129, 832-838. DOI: 10.1002/ijc. 25756

(143) Zhang, X.; Wang, D.; Li, Z.; Jiao, D.; Jin, L.; Cong, J.; Zheng, X.; Xu, L., LowDose Gemcitabine Treatment Enhances Immunogenicity and Natural Killer CellDriven Tumor Immunity in Lung Cancer. Front.Immunol. 2020, 11, 331. DOI: 10.3389/fimmu.2020.00331 
(144) Liu, J.-Y.; Wu, Y.; Zhang, X.-S.; Yang, J.-L.; Li, H.-L.; Mao, Y.-Q.; Wang, Y.; Cheng, X.; Li, Y.-Q.; Xia, J.-C.; Masucci, M.; Zeng, Y.-X., Single administration of low dose cyclophosphamide augments the antitumor effect of dendritic cell vaccine. Cancer Immunol.Immunother. 2007, 56, 1597-1604. DOI: 10.1007/s00262-007-03054

(145) Castano, A. P.; Mroz, P.; Wu, M. X.; Hamblin, M. R., Photodynamic therapy plus low-dose cyclophosphamide generates antitumor immunity in a mouse model. Proc. Natl. Acad. Sci. U.S.A. 2008, 105, 5495-5500. DOI: 10.1073/pnas.0709256105

(146) Hughes, E.; Scurr, M.; Campbell, E.; Jones, E.; Godkin, A.; Gallimore, A., T-cell modulation by cyclophosphamide for tumour therapy. Immunology 2018, 154, 62-68. DOI: $10.1111 /$ imm.12913

(147) Liu, Y.; Dong, Y.; Kong, L.; Shi, F.; Zhu, H.; Yu, J., Abscopal effect of radiotherapy combined with immune checkpoint inhibitors. J. Hematol.Oncol. 2018, 11, 104 DOI: 10.1186/s13045-018-0647-8

(148) Abuodeh, Y.; Venkat, P.; Kim, S., Systematic review of case reports on the abscopal effect. Curr Probl Cancer 2016, 40, 25-37. DOI: 10.1016/j.currproblcancer.2015.10.001

(149) Stamell, E. F.; Wolchok, J. D.; Gnjatic, S.; Lee, N. Y.; Brownell, I., The Abscopal Effect Associated With a Systemic Anti-melanoma Immune Response. Int. J. Radiat. Oncol. Biol. Phys. 2013, 85, 293-295. DOI: 10.1016/j.ijrobp.2012.03.017

(150) Patel, R. B.; Ye, M.; Carlson, P. M.; Jaquish, A.; Zangl, L.; Ma, B.; Wang, Y.; Arthur, I.; Xie, R.; Brown, R. J.; Wang, X.; Sriramaneni, R.; Kim, K.; Gong, S.; Morris, Z. S., Development of an In Situ Cancer Vaccine via Combinational Radiation and Bacterial-Membrane-Coated Nanoparticles. Adv. Mater. 2019, 31, 1902626. DOI: 10.1002/adma.201902626

(151) Demaria, S.; Golden, E. B.; Formenti, S. C., Role of Local Radiation Therapy in Cancer Immunotherapy. JAMA Oncol. 2015, 1, 1325-1332. DOI: 10.1001/jamaoncol.2015.2756

(152) Huang, Y.; Goel, S.; Duda, D. G.; Fukumura, D.; Jain, R. K., Vascular Normalization as an Emerging Strategy to Enhance Cancer Immunotherapy. Cancer Res. 2013, 73, 2943-2948. DOI: 10.1158/0008-5472.CAN-12-4354

(153) Farsaci, B.; Donahue, R. N.; Coplin, M. A.; Grenga, I.; Lepone, L. M.; Molinolo, A. A.; Hodge, J. W., Immune Consequences of Decreasing Tumor Vasculature with Antiangiogenic Tyrosine Kinase Inhibitors in Combination with Therapeutic Vaccines. Cancer Immunol.Res. 2014, 2, 1090-1102. DOI: 10.1158/2326-6066.CIR-14-0076

(154) Huang, Y.; Yuan, J.; Righi, E.; Kamoun, W. S.; Ancukiewicz, M.; Nezivar, J.; Santosuosso, M.; Martin, J. D.; Martin, M. R.; Vianello, F.; Leblanc, P.; Munn, L. L.; Huang, P.; Duda, D. G.; Fukumura, D.; Jain, R. K.; Poznansky, M. C., Vascular normalizing doses of antiangiogenic treatment reprogram the immunosuppressive tumor microenvironment and enhance immunotherapy. Proc. Natl. Acad. Sci. U.S.A. 2012, 109, 17561-17566. DOI: 10.1073/pnas.1215397109

(155) Tan, G. H.; Tian, L.; Wei, Y. Q.; Zhao, X.; Li, J.; Wu, Y.; Wen, Y. J.; Yi, T.; Ding, Z. Y.; Kan, B.; Mao, Y. Q.; Deng, H. X.; Li, H. L.; Zou, C. H.; Fu, C. H., Combination of low-dose cisplatin and recombinant xenogeneic endoglin as a vaccine 
induces synergistic antitumor activities. Int. J. Cancer 2004, 112, 701-706. DOI: 10.1002/ijc.20449

(156) Lokhov, P. G.; Balashova, E. E., Design of universal cancer vaccines using natural tumor vessel-specific antigens (SANTAVAC). Hum Vaccin Immunother 2015, 11, 689-698. DOI: 10.1080/21645515.2015.1011022

(157) Arens, R., Rational Design of Vaccines: Learning from Immune Evasion Mechanisms of Persistent Viruses and Tumors. In Advances in Immunology, Vol 114: Synthetic Vaccines, Melief, C. J. M., Ed. 2012; Vol. 114, pp 217-243. DOI: 10.1016/B978-0-12-396548-6.00009-3

(158) Kulkarni, A.; Chandrasekar, V.; Natarajan, S. K.; Ramesh, A.; Pandey, P.; Nirgud, J.; Bhatnagar, H.; Ashok, D.; Ajay, A. K.; Sengupta, S., A designer self-assembled supramolecule amplifies macrophage immune responses against aggressive cancer. Nat. Biomed.Eng. 2018, 2, 589-599. DOI: 10.1038/s41551-018-0254-6

(159) Koh, E.; Lee, E. J.; Nam, G.-H.; Hong, Y.; Cho, E.; Yang, Y.; Kim, I.-S., Exosome-SIRP alpha, a CD47 blockade increases cancer cell phagocytosis. Biomaterials 2017, 121, 121-129. DOI: 10.1016/j.biomaterials.2017.01.004

(160) Rukmini, S. J.; Bi, H.; Sen, P.; Everhart, B.; Jin, S.; Ye, K., Inducing Tumor Suppressive Microenvironments through Genome Edited CD47(-/-) Syngeneic Cell Vaccination. Sci. Rep. 2019, 9, 20057. DOI: 10.1038/s41598-019-56370-6

(161) Li, Y.; Zhang, M.; Wang, X.; Liu, W.; Wang, H.; Yang, Y.-G., Vaccination with CD47 deficient tumor cells elicits an antitumor immune response in mice. Nat. Commun. 2020, 11, 581-581. DOI: 10.1038/s41467-019-14102-4

(162) Zheng, Y.; Yin, G.; Le, V.; Zhang, A.; Chen, S.; Liang, X.; Liu, J., Photodynamictherapy Activates Immune Response by disrupting Immunity Homeostasis of Tumor Cells, which Generates Vaccine for Cancer Therapy. Int. J. Biol. Sci. 2016, 12, 120132. DOI: $10.7150 /$ ijbs.12852

(163) Zheng, D.-W.; Gao, F.; Cheng, Q.; Bao, P.; Dong, X.; Fan, J.-X.; Song, W.; Zeng, X.; Cheng, S.-X.; Zhang, X.-Z., A vaccine-based nanosystem for initiating innate immunity and improving tumor immunotherapy. Nat. Commun. 2020, 11, 1985. DOI: 10.1038/s41467-020-15927-0 
TOC

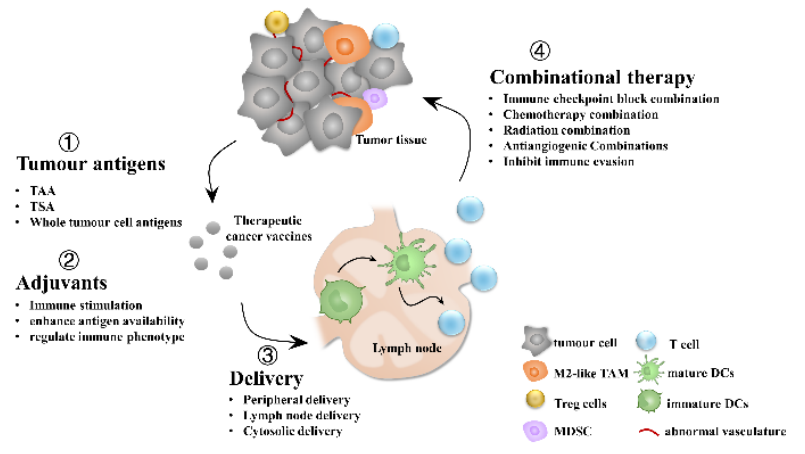

